\title{
5-Formylcytosine could be a semi-permanent base in specific genome sites
}

\author{
Meng Su, Angie Kirchner, Samuele Stazzoni, Markus Müller, Mirko Wagner, Arne Schröder and \\ Thomas Carel**a]
}

Center for Integrated Protein Science at the Department of Chemistry. Ludwig-Maximilians-Universität München, Butenandtstrasse 5-13, 81377 München (Germany), E-mail: thomas.carell@Imu.de Homepage: http://www.carellgroup.de

Published 25.08.2016 in Angewandte Chemie International Edition, https://doi.org/10.1002/anie.201605994

\begin{abstract}
Formyl-2'-deoxycytosine (fdC) is a recently discovered epigenetic base in the genome of stem cells, with yet unknown functions. Sequencing data show that the base is enriched in $\mathrm{CpG}$ islands of promoters and hence likely involved in the regulation of transcription during cellular differentiation. $\mathrm{fdC}$ is known to be recognized and excised by the enzyme thymine-DNA-glycosylase (Tdg). As such, fdC is believed to function as an intermediate during active demethylation. In order to understand the function of the new epigenetic base $\mathrm{fdC}$, it is important to analyze its formation and removal at defined genomic sites. Here, we report a new method that combines sequence-specific chemical derivatization of $\mathrm{fdC}$ with droplet digital PCR that enables such analysis. We show initial data, indicating that the repair protein Tdg removes only $50 \%$ of the fdCs at a given genomic site, arguing that fdC is a semi-permanent base.
\end{abstract}

DNA contains besides the sequence information a second, epigenetic information level, which encodes how actively the controlled gene is transcribed. ${ }^{[1]}$ Today, next to the four canonical bases, four additional epigenetic bases are known. ${ }^{[2]}$ These are 5-methylcytosine $(5 \mathrm{mC}), 5$-hydroxymethylcytosine $(5 \mathrm{hmC}),{ }^{[3]} 5$-formylcytosine $(5 \mathrm{fC}),{ }_{,}^{[4]}$ and 5 -carboxycytosine $(5 \mathrm{caC}) .{ }^{[5]}$ (Figure 1a) Over the last years, sensitive mass spectrometry-based methods have helped to reveal the global levels of these epigenetic bases in stem cells ${ }^{[4,6]}$ and tissues including the brain. ${ }^{[7]}$ In order to learn about the levels and the distribution of the epigenetic bases at specific sites in the genome, different sequencing methods were developed ${ }^{[8]}$ in which selective chemical derivatization of the bases is performed ${ }^{[9]}$, sometimes in combination with bisulfite sequencing. ${ }^{[9 c, 10]}$ Although these methods provide information about the distribution of the bases at a given time point, it is a hallmark of epigenetic information that it changes dynamically. To gain deeper insight into the dynamics of the epigenetic information layer at a single position in the genome, it is therefore essential to develop methods that allow following the changes of, for example, $\mathrm{fdC}$ at a specific location in the genome over time. ${ }^{[11]}$ A perfect method will ultimately allow parallel monitoring of fdC dynamics at different genomic sites.

The central question addressed in this manuscript is: Are the measured global data of the past averages from different processes at different positions in the genome, or do they reflect what is happening at an individual site in the genome. To answer this question, we developed a sequence specific chemical derivatization method that allows in combination with droplet digital PCR to monitor the epigenetic base $\mathrm{fdC}$ at different loci directly in the genome of stem cells.

a)<smiles>Cc1cn(C)c(=O)n1N</smiles>

$\mathrm{mC}$<smiles>Cn1cc(CO)c(N)nc1=O</smiles>

$\mathrm{hmC}$<smiles>Cn1cc(C=O)c(N)nc1=O</smiles>

fC<smiles></smiles>

caC

b)
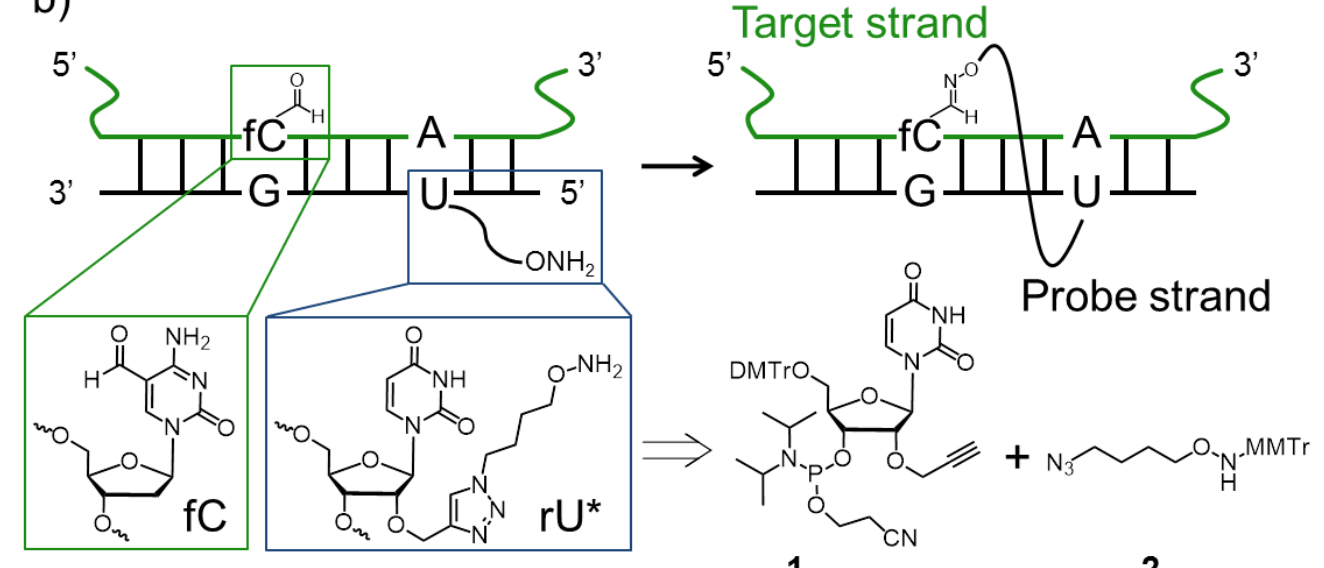

1

Figure 1. a) Structures of cytosine epigenetic modifications; b) Schematic representation of the fdC detection strategy, and used building blocks including the click chemistry-based assembly of the $\mathrm{rU}^{*}$ probe molecule. 
For the sequence specific localization of $\mathrm{fdC}$ in the genome, we utilize a small probe oligonucleotide (Figure 1b, Table S1), which contains a hydroxylamine tether that is able to form a covalent linkage with $\mathrm{fdC}$ so that the probe strand is subsequently tightly bound to the target. ${ }^{[4]}$ We examined systematically different linker lengths, linker attachment points and distances. Best results were obtained when we incorporated the 2'-O-propargyl uridine using its phosphoramidite 1 into the probe oligonucleotide and attached the azido-C4hydroxylamine 2 using the $\mathrm{Cu}(\mathrm{I})$-catalyzed version (click reaction) of the Huisgen-reaction. ${ }^{[12]}$ We protected the hydroxylamine unit for the click reaction with a monomethoxytrityl group (MMTr), which was cleaved afterwards with acetic acid at $25^{\circ} \mathrm{C}$. This brief exposure of the probe oligonucleotide to acidic conditions did not cause significant depurination. After solid-phase synthesis, click modification of the oligonucleotide and a final purification step (Figure S1), we obtained oligonucleotides with different sequences and lengths containing an $\mathrm{rU}$-hydroxylamine base $\left(\mathrm{rU}^{*}\right)$ at different positions for reaction with the fdC-base on the target strand. For the following experiments, we prepared 13-mer long oligonucleotides.

To investigate at which position the linker in the probe strand would react best with $\mathrm{fdC}$ in the target strand, we varied the position of $\mathrm{rU}^{*}$ relative to $\mathrm{fdC}$ and explored different reaction conditions (data not shown). Excellent results were finally obtained when probe strand $\mathbf{P 1}$, containing $\mathrm{rU}^{*}$ exactly 4 basepairs in 5' direction relative to fdC, was hybridized to the fdC target strand $\mathbf{T} 1$ in the presence of catalytic amounts of 4-methoxyaniline (Fig 2a). With this catalyst, the crosslinking reaction is complete after $24 \mathrm{~h}$ with yields exceeding $95 \%$. Without the catalyst, only about $50 \%$ yield could be obtained (Fig $2 b$ ).

In order to increase the rate of the reaction, we tested other catalysts. We observed the best results when we used 1,4diaminobenzene as a catalyst, in which case the crosslinking reaction between $\mathbf{T} 1$ and $\mathbf{P 1}$ is completed already after $3 \mathrm{~h}$ (Figure 2c). Duplex formation (T1:P1) was analyzed using denaturing PAGE and quantified by fluorescence (Figure 2d).

When $\mathrm{fdC}$ is located one base pair further away from $\mathrm{rU}^{*}$ without changing the probe strand, we observe slower reaction (Figure $\mathrm{S} 2$ ). These results show that $\mathrm{rU}^{*}$ placed four or five bases away from fdC in 5'-direction to fdC allows the tether to reach the formyl group of fdC via the major groove of the duplex (Figure S3).

T1: 5'-GTAATGFCGCTAGG-3'

P1: 3'-CATTACGCGAU*CC-5'

a)

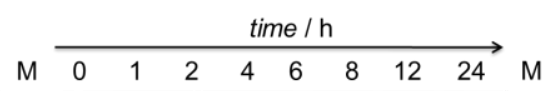

b)
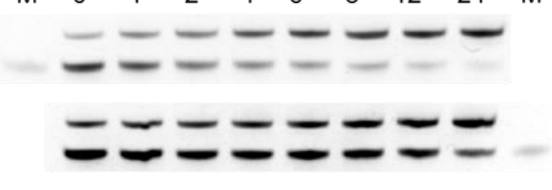

c)

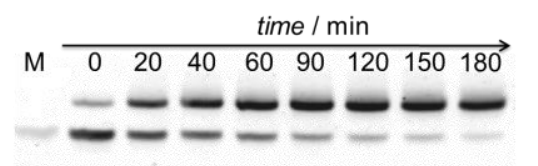

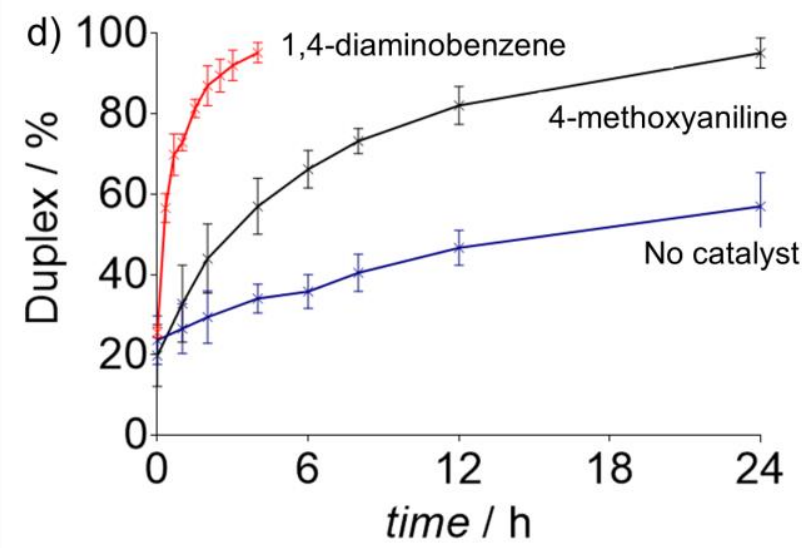

Figure 2. Denaturing PAGE gel showing the duplex formation between $\mathrm{T} 1$ and $\mathrm{P} 1$ at $25^{\circ} \mathrm{C}$ : a) with the catalyst 4-methoxyaniline; b) without a catalyst; c) with the catalyst 1,4-diaminobenzene; d) Quantification of the DNA duplex formation during the reaction. Black: catalyst 4-methoxyaniline, blue: no catalyst, red: catalyst 1,4-diaminobenzene. Error bars represent the standard error of the mean calculated from three replicates. Conditions: $2 \mu \mathrm{M}$ oligonucleotides, $100 \mathrm{mM} \mathrm{NaCl}, 10 \mathrm{mM}$ $\mathrm{NaOAc}$ buffer $\mathrm{pH}$ 6.0, $10 \mathrm{mM}$ 4-methoxyaniline. $\mathrm{M}$ = single strand marker. The time point 0 is after re-annealing.

MALDI-TOF data confirmed that the crosslinks form as expected (Figure S4). For the reacted duplex T1:P1, we obtained the correct molecular weight for the duplex with $\mathrm{m} / \mathrm{z}_{\text {found }}=8081.9\left(\mathrm{~m} / \mathrm{z}_{\mathrm{calc}}=8084.7\right)$. As expected, the oxime formation reaction between T1 and $\mathbf{P 1}$ leads to a higher melting temperature of the hybridized and reacted duplex (Figure S5). Typically, we observed that the uncrosslinked $13-$ mer duplex melts at around $44^{\circ} \mathrm{C}$. The duplex after crosslink formation shows a melting temperature of above $80^{\circ} \mathrm{C}$.

Because pyrimidine bases are able to react with nucleophiles also at the C6 position in a Michael-type reaction, which is the basis for bisulfite sequencing, we next tested if the reaction of $\mathrm{rU}^{*}$ is possible with other pyrimidines (Figure 3). To our delight, hybridization of the $\mathrm{rU}^{*}$-containing probe strand with target strands containing dT, dC, mdC, hmdC and cadC (T3-8) gave no reaction. Reaction is, however, observed with abasic sites. This is important because fdC and cadC are substrates for base excision repair and hence could in principle be precursors for abasic sites. ${ }^{[13]}$ In this sense, $\mathrm{rU}^{*}$ always reports the presence of $\mathrm{fdC}$ and also potentially of fdC and cadC derived abasic sites.

T3-8: 5'-GTAATGXGCTAGG-3'

P1: 3'-CATTACGCGAU*CC-5'

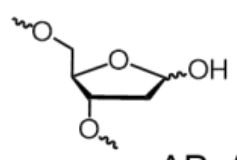

AP: Abasic site

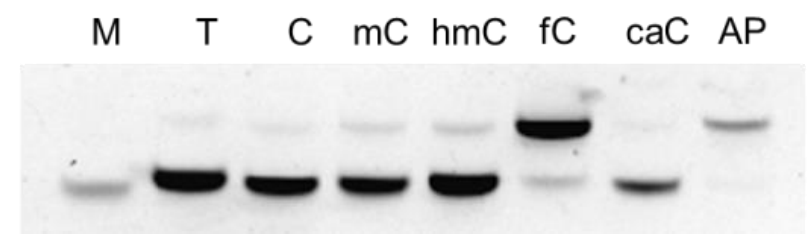

Figure 3. Denaturing PAGE gel showing duplex formation of T3-8 and P1 at $25^{\circ} \mathrm{C}$ after $24 \mathrm{~h}$. 
We finally turned the sequence specific fdC detection possibility into a method for detecting single fdC bases at a defined position in whole genomes. To this end, we coupled the chemistry to droplet digital PCR ${ }^{[14]}$-based amplification and readout.

Genomic target DNA (Tg) was in the first step isolated from mouse embryonic stem cells (mESCs) at different time points during priming from naïve cells. We also isolated genomic DNA from mESCs with a knockout of the Tdg repair enzyme (Tdg $\left.{ }^{-/}\right)$to block excision and repair of $\mathrm{fdC}$ and cadC. We finally also isolated genomic DNA from mESCs lacking any of the three methyltransferases (Dnmt1, $3 a$ and $3 b)$. These stem cells lack $m d C$ and are hence unable to produce the oxidized $x d C$ ( $x=\mathrm{hm}$, $f$ and ca) epigenetic bases. This genomic DNA served in our studies consequently as a negative control. For analysis, we selected two different fdC sites that were reported to have high fdC contents. ${ }^{[10 \mathrm{c}]}$ We focused initially on the $30,020,539^{\text {th }}$ site of chromosome 16 Mus musculus (MM9) located on the exon 3 of $632428 \mathrm{C} 04 \mathrm{Rik}$. It was found to contain $23 \%$ of $\mathrm{fdC}$ based on redBS-Sequencing. The second site we studied was the $8,846,677^{\text {th }}$ site of chromosome 15 which is located in non-coding DNA. This site was reported to contain $32 \%$ of fdC.

For the first site, we reacted a 25 -mer probe (P2, SI) containing the $\mathrm{rU}^{*}$ base with $\mathrm{Tg}$ using 1,4-diaminobenzene as catalyst. In the absence of fdC, a covalent bond between $\mathbf{P} 2$ and $\mathbf{T g}$ cannot form. To remove the excess of probe, we loaded the Tg:P2 complex onto an NEB Monarch DNA cleanup column and rinsed the column with wash buffer to elute oligonucleotides shorter than 50-mer, which is the unbound P2. After this washing, we eluted the Tg:P2 with TE buffer. UV/Vis analysis of the eluted material showed a typical gDNA spectrum. We next added a 70-mer 5'-phosphorylated reporter strand (R1, SI) which hybridizes with an 18-nt stretch directly adjacent to the probe strand and ligated both probe and the reporter at $60^{\circ} \mathrm{C}$ by addition of Ampligase to form R1-P2 as depicted schematically in Figure 4a.

a)

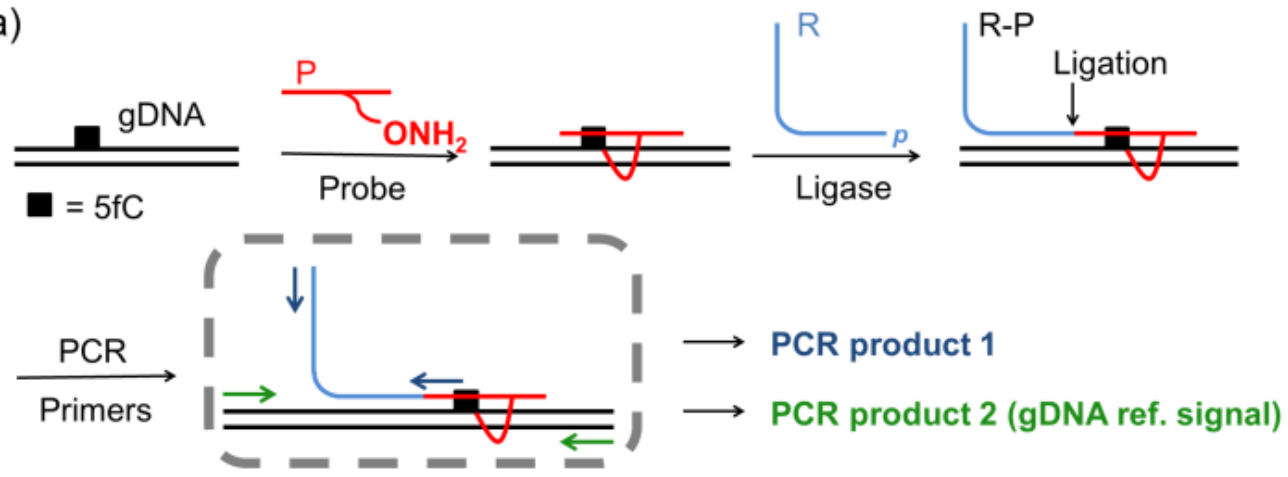

b)

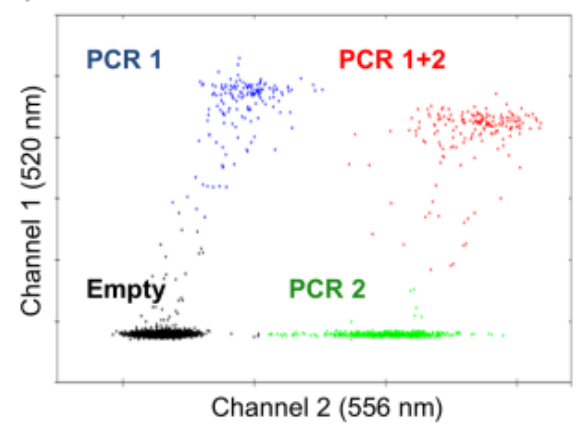

c)

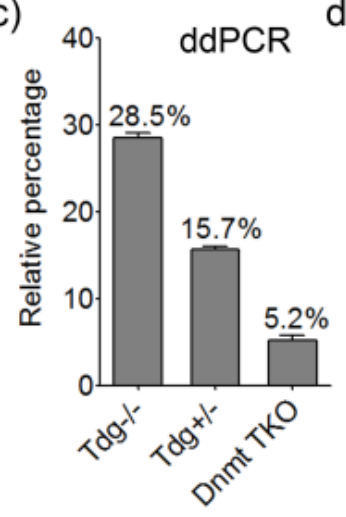

d)

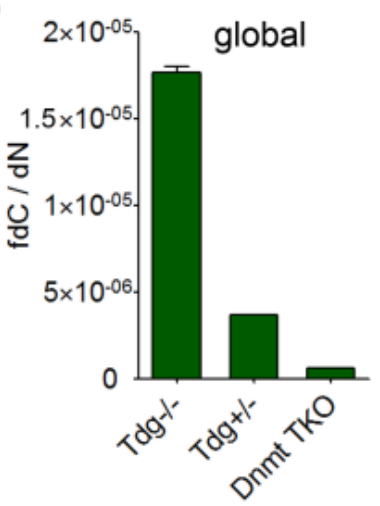

e)

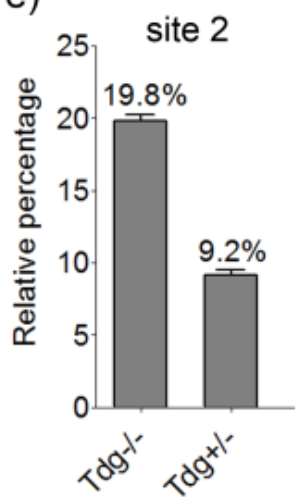

f)

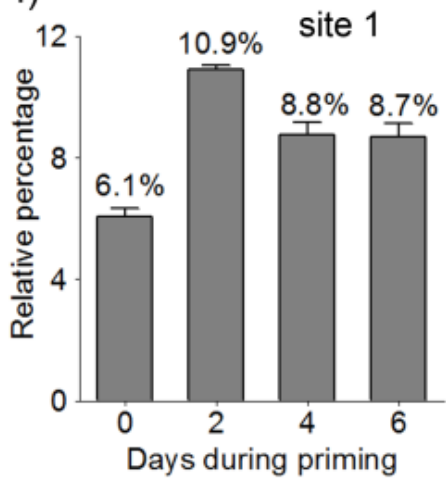

g)

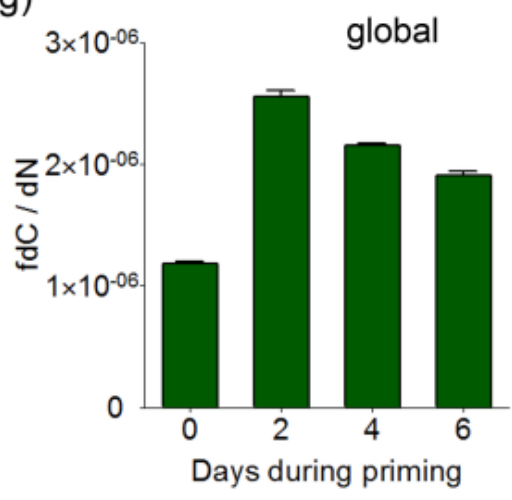

Figure 4. The fdC sequencing method: a) Schematic representation of the method, black line: gDNA; red segments: fdC probe; blue segments: reporter strands; arrows: PCR primer pairs; b) Typical 2-D plot of droplet fluorescence; c) Cluster ratios for position 1 in Tdg-/-, Tdg+/- and Dnmt TKO mES cells; d) Global fdC quantification in Tdg-/-, Tdg+/- and Dnmt TKO mES cells using our LC-MS method; e) Cluster ratios for position 2 in Tdg-/- and Tdg+/- mES cells; f) Cluster ratios for position 1 in wild-type mES cells at different days after priming; g) Global quantification data for the wild-type mES cells measured by LC-MS. 
We next added two sets of primers to the assay (blue and green arrows, Figure 4a) to amplify the ligation product relative to the target duplex. Importantly, the blue primers recognize only the hybrid R1-P2 probe generated in the ligation step while the green primers indicate the presence of gDNA. The amplification was monitored with two different TaqMan probes which showed fluorescence at 520 and $556 \mathrm{~nm}$. This relative detection is needed to normalize on the amount of input gDNA. Because conventional real-time PCR is known to become inaccurate when copy number differences less than the 10-fold need to be resolved, we used droplet digital PCR. In this method, small droplets are generated with one droplet containing a maximum of one of the fully assembled analysis constructs shown in Figure 4a. The PCR reaction takes place in the droplets, producing a specific signal. Subsequent color-counting of each individual droplet yields numbers from which one can accurately calculate the amount of $\mathrm{fdC}$, even if the fdC values are very low. $\mathrm{A}$ representative plot of the data is given in Figure 4b. Empty drops give no PCR signal (black dots in Figure 4b). Drops containing only Tg give only the PCR signal from the green primers (green dots in Figure $4 \mathrm{~b}$ ). Blue dots are obtained due to the dissociation of the ligated product R1-P2 from $\mathbf{~ g g}$ in the ligation process which is performed at $60^{\circ} \mathrm{C}$ for $10 \mathrm{~h}$. The red signals are finally generated from droplets that contain both PCR products. For the calculation, please see the Supporting Information.

Using the method, we first studied mES cells lacking the Tdg enzyme $\left(\mathrm{Tdg}^{-1}\right)$. A rather high level of $28.5 \%$ fdC was measured at the first locus (Figure 4c) in agreement with the results from redBS-seq. ${ }^{[10 c]}$ When we performed the study, however, with mESCs having an active Tdg repair enzyme $\left(\mathrm{Tdg}^{+/}\right)$we measured that the fdC level drops at this particular position to $15.7 \%$ (Figure $\left.4 \mathrm{c}\right)$. This is very important because it shows that Tdg removes only half of the fdCs at a given site and also unusual due to the fact that repair glycosylases are known to find basically all possible substrates. The result underpins the high dynamics of fdC formation and repair at a given site. When we studied the fdC content at this location in mESCs lacking any methyltransferase (Dnmt TKO) the fdC level drops as expected to a little more than $5 \%$, showing that the reported levels of $\mathrm{fdC}$ in the $\mathrm{Tdg}^{+/}$cells are real and not an artifact. In order to elucidate if single-site fdC levels (Figure 4c) follow global genomic fdC levels, we quantified the total levels of fdC in these cells (Figure 4d). These global data are in good agreement with the data obtained from single site fdC quantifications. Thus, our new data make a scenario where $\mathrm{fdC}$ is fully removed at one site and shielded from repair at another place unlikely. Instead, fdC is even at a given position only partially removed in a cell population. Alternatively, it may be that Tdg removes fdC differently on the two chromosomes, which however needs further investigation.

In order to verify the data, we repeated the Tdg study at a second genomic site $\left(8,846,677^{\text {th }}\right.$ nucleoside of chromosome 15$)$. For this site, we designed a new probe strand P3 and a new reporter strand R2 and performed again ddPCR with two sets of primers (Figure S5). Comparing the data obtained from $\mathrm{Tdg}^{-/}$cells with the data from $\mathrm{Tdg}^{+/-}$cells, again only a $50 \%$ reduction of the fdC level is shown at this position, in full agreement with the data above obtained from the first position (Figure 4e).

We finally performed a kinetic study in which we monitored the fdC development at the first position during priming of stem cells (Figure 4f). We see that the $\mathrm{fdC}$ levels rise at the given position with a strong increase in the early phase of priming, followed by a small decline phase and finally stable values (Figure 4f) again in agreement with the global data that we again measured using our reported method (Fig 4g).

The fact that our method is providing the same trends as seen in the global data at a single genomic site makes us confident that our method is robust and reliable reporting what happens at an individual site. Because single-site and global data go in parallel, we have now first evidence that the reported global trends are reflecting what happens at each individual fdC site, rather than evening out largely different dynamics at separate sites. Another interesting result of this study is that the repair enzyme Tdg removes only half of the $\mathrm{fdC}$ bases at a given genomic site in an mESC population, which argues that $\mathrm{fdC}$ is a semi-permanent base at a given position in the genome.

\section{Experimental Section}

Probe crosslinking gDNA solution $(1.2 \mu \mathrm{g})$, fdC probe $(1 \mu \mathrm{M}, 2 \mu \mathrm{L}), \mathrm{NaH}_{2} \mathrm{PO}_{4}-\mathrm{Na}_{2} \mathrm{HPO}_{4}$ buffer $(200 \mathrm{mM}, \mathrm{pH}=6.0,2 \mu \mathrm{L}), \mathrm{NaCl}$ aq. $(1.5 \mathrm{M}, 2 \mu \mathrm{L})$, and $\mathrm{dd}_{2} \mathrm{O}$ were mixed to a final volume of $18 \mu \mathrm{L}$. The mixture was heated to $95^{\circ} \mathrm{C}$ for 3 min and then cooled down rapidly to $25^{\circ} \mathrm{C}$. $1,4-\mathrm{Benzenediamine}$ aq $\left(10 \mathrm{mM}, 2 \mu \mathrm{L}\right.$ ) was added and the reaction vial was shaken for $6 \mathrm{~h}$ at $25^{\circ} \mathrm{C}$. The mixture was neutralized with $\mathrm{Na}_{2} \mathrm{HPO}{ }_{4}$ aq. $(200 \mathrm{mM}, 40 \mu \mathrm{L})$ before purification with the NEB Monarch PCR DNA Cleanup Kit.

Ligation The above described gDNA solution (300 ng), reporter strand ( $20 \mathrm{nM}, 1 \mu \mathrm{L})$, Ampligase reaction buffer (10×, $2 \mu \mathrm{L})$, Ampligase from Epicentre $\left(5 \mathrm{U} / \mu \mathrm{L}, 2 \mu \mathrm{L}, 10 \mathrm{U}\right.$ ) and $\mathrm{ddH}_{2} \mathrm{O}$ were mixed to a final volume of $20 \mu \mathrm{L}$. The mixture was heated to $95^{\circ} \mathrm{C}$ for $3 \mathrm{~min}$, and then $94^{\circ} \mathrm{C}$ for $1 \mathrm{~min}, 60^{\circ} \mathrm{C}$ for $1 \mathrm{~h}$ and back to $94^{\circ} \mathrm{C}$ for 10 cycles. Then, the reaction mixture was diluted with Tris- $\mathrm{HCl}$ buffer $(200 \mathrm{mM}, \mathrm{pH}=7.6,50 \mu \mathrm{L})$ before purification using the NEB Monarch PCR DNA Cleanup Kit.

Droplet digital PCR ddPCR was conducted on a Bio-Rad QX100 ddPCR System. For one reaction, gDNA (6 ng), four primers (18 $\mu \mathrm{M}$ each, $1 \mu \mathrm{L})$, two TaqMan probes ( $5 \mu \mathrm{M}$ each, $1 \mu \mathrm{L}$ ), digital PCR Supermix for Probes (no dUTP, $2 \times, 10 \mu \mathrm{L}$ ), and ddH $\mathrm{O}_{2} \mathrm{O}$ were mixed to a final volume of $20 \mu \mathrm{L}$. PCR cycle: $95^{\circ} \mathrm{C}$ for $10 \mathrm{~min}, 94^{\circ} \mathrm{C}$ for $30 \mathrm{sec}$ and $64^{\circ} \mathrm{C}$ for $1 \mathrm{~min}$ for 35 cycles, then $98^{\circ} \mathrm{C}$ for $10 \mathrm{~min}$ and cooled down to $12^{\circ} \mathrm{C}$, with a temperature ramp of $2^{\circ} \mathrm{C} / \mathrm{s}$. For a detailed description please see the Supporting Information.

\section{Acknowledgements}

We thank K. Hufnagel for preparing the phosphoramidites of the epigenetic bases. This project has received funding from Deutsche Forschungsgemeinschaft SFB1032 and the Excellence Cluster CiPS ${ }^{\mathrm{M}}$ (EXC114). Further support is obtained from the European Union's Horizon 2020 research and innovation program under grant agreement No. 642023 (ITN clickgene). 
Keywords: epigenetic bases $•$ click chemistry $\bullet 5$-formylcytosine $\bullet$ genomic DNA $•$ droplet digital PCR

[1] P. A. Jones, Nat. Rev. Genet. 2012, 13, 484-492.

[2] T. Carell, C. Brandmayr, A. Hienzsch, M. Müller, D. Pearson, V. Reiter, I. Thoma, P. Thumbs, M. Wagner, Angew. Chem., Int. Ed. 2012, 51, 7110-7131; Angew. Chem. 2012, 124, 7220-7242.

[3] a) S. Kriaucionis, N. Heintz, Science 2009, 324, 929-930; b) M. Tahiliani, K. P. Koh, Y. Shen, W. A. Pastor, H. Bandukwala, Y. Brudno, S. Agarwal, L. M. lyer, D. R. Liu, L. Aravind, A. Rao, Science 2009, 324, 930-935.

[4] T. Pfaffeneder, B. Hackner, M. Truss, M. Münzel, M. Müller, C. Deiml, C. Hagemeier, T. Carell, Angew. Chem., Int. Ed. 2011, 50, 7008-7012; Angew. Chem. 2011, 123, 7146-7150.

[5] a) S. Ito, L. Shen, Q. Dai, S. C. Wu, L. B. Collins, J. A. Swenberg, C. He, Y. Zhang, Science 2011, 333, 1300-1303; b) Y.-F. He, B.-Z. Li, Z. Li, P. Liu, Y. Wang, Q. Tang, J. Ding, Y. Jia, Z. Chen, L. Li, Y. Sun, X. Li, Q. Dai, C.-X. Song, K. Zhang, C. He, G.-L. Xu, Science 2011, 333, $1303-1307$.

[6] S. Schiesser, B. Hackner, T. Pfaffeneder, M. Müller, C. Hagemeier, M. Truss, T. Carell, Angew. Chem., Int. Ed. 2012, 51, 6516-6520; Angew. Chem. 2012, $124,6622-6626$.

[7] a) M. Münzel, D. Globisch, T. Brückl, M. Wagner, V. Welzmiller, S. Michalakis, M. Müller, M. Biel, T. Carell, Angew. Chem., Int. Ed. 2010, 49, 5375-5377; Angew. Chem. 2010, 122, 5503-5505; b) D. Globisch, M. Münzel, M. Müller, S. Michalakis, M. Wagner, S. Koch, T. Brückl, M. Biel, T. Carell, PLoS ONE 2010, 5, e15367; c) M. Wagner, J. Steinbacher, T. F. J. Kraus, S. Michalakis, B. Hackner, T. Pfaffeneder, A. Perera, M. Müller, A. Giese, H. A. Kretzschmar, T. Carell, Angew. Chem., Int. Ed. 2015, 54, 12511-12514; Angew. Chem. 2015, 127, 12691-12695.

[8] a) N. Plongthongkum, D. H. Diep, K. Zhang, Nat. Rev. Genet. 2014, 15, 647-661; b) M. J. Booth, E.-A. Raiber, S. Balasubramanian, Chem. Rev. 2015, 115, 2240-2254.

[9] a) W. A. Pastor, U. J. Pape, Y. Huang, H. R. Henderson, R. Lister, M. Ko, E. M. McLoughlin, Y. Brudno, S. Mahapatra, P. Kapranov, M. Tahiliani, G. Q. Daley, X. S. Liu, J. R. Ecker, P. M. Milos, S. Agarwal, A. Rao, Nature 2011, 473, 394-397; b) E.-A. Raiber, D. Beraldi, G. Ficz, H. Burgess, M. Branco, P. Murat, D. Oxley, M. Booth, W. Reik, S. Balasubramanian, Genome Biol. 2012, 13, R69; c) C.-X. Song, Keith E. Szulwach, Q. Dai, Y. Fu, S.-Q. Mao, L. Lin, C. Street Y. Li, M. Poidevin, H. Wu, J. Gao, P. Liu, L. Li, G.-L. Xu, P. Jin, C. He, Cell 2013, 153, 678-691; d) B. Xia, D. Han, X. Lu, Z. Sun, A. Zhou, Q. Yin, H. Zeng, M. Liu, X. Jiang, W. Xie, C. He, C. Yi, Nat. Methods 2015, 12, 1047-1050.

[10] a) M. Yu, Gary C. Hon, Keith E. Szulwach, C.-X. Song, L. Zhang, A. Kim, X. Li, Q. Dai, Y. Shen, B. Park, J.-H. Min, P. Jin, B. Ren, C. He, Cell 2012, 149, 1368-1380; b) M. J. Booth, M. R. Branco, G. Ficz, D. Oxley, F. Krueger, W. Reik, S. Balasubramanian, Science 2012, 336, 934-937; c) M. J. Booth, G. Marsico, M. Bachman, D. Beraldi, S. Balasubramanian, Nat. Chem. 2014, 6, 435-440; d) X. Lu, C.-X. Song, K. Szulwach, Z. Wang, P. Weidenbacher, P. Jin, C. He, J. Am. Chem. Soc. 2013, 135, 9315-9317.

[11] a) A. Nomura, K. Sugizaki, H. Yanagisawa, A. Okamoto, Chem. Commun. 2011, 47, 8277-8279; b) J. Duprey, G. A. Bullen, Z.-Y. Zhao, D. M. Bassani, A. F. A. Peacock, J. Wilkie, J. H. R. Tucker, ACS Chem. Bio. 2016, 11, 717-721.

[12] a) P. M. E. Gramlich, S. Warncke, J. Gierlich, T. Carell, Angew. Chem., Int. Ed. 2008, 47, 3442-3444; Angew. Chem. 2008, 120, 3491-3493.; b) J. Willibald, J. Harder, K. Sparrer, K.-K. Conzelmann, T. Carell, J. Am. Chem. Soc. 2012, 134, 12330-12333.

[13] A. Maiti, A. C. Drohat, J. Biol. Chem. 2011, 286, 35334-35338.

[14] B. J. Hindson, K. D. Ness, D. A. Masquelier, P. Belgrader, N. J. Heredia, A. J. Makarewicz, I. J. Bright, M. Y. Lucero, A. L. Hiddessen, T. C. Legler, T. K. Kitano, M. R. Hodel, J. F. Petersen, P. W. Wyatt, E. R. Steenblock, P. H. Shah, L. J. Bousse, C. B. Troup, J. C. Mellen, D. K. Wittmann, N. G. Erndt, T. H. Cauley, R. T. Koehler, A. P. So, S. Dube, K. A. Rose, L. Montesclaros, S. Wang, D. P. Stumbo, S. P. Hodges, S. Romine, F. P. Milanovich, H. E. White, J. F. Regan, G. A. Karlin-Neumann, C. M. Hindson, S. Saxonov, B. W. Colston, Anal. Chem. 2011, 83, 8604-8610.

[15] M. Wendeler, L. Grinberg, X. Wang, P. E. Dawson, M. Baca, Bioconjugate Chem. 2014, 25, 93-101. 


\section{Table of contents}

1. General methods of organic synthesis

2. Synthesis of the hydroxylamine linker

3. ${ }^{1} \mathrm{H}-\mathrm{NMR}$ spectra of the linker

4. General methods for oligonucleotide synthesis

5. Crosslinking studies with the synthesized strands

6. Experimental details of the genomic fdC profiling study

7. Quantification modeling

8. Droplet digital PCR data 


\section{General methods of organic synthesis}

Chemicals were purchased from Sigma-Aldrich and used without further purification. The solvents for organic synthesis were of reagent grade and purified by distillation. Solutions were concentrated in vacuo on a Heidolph rotary evaporator with a Vario PC2001 diaphragm pump by Vacuubrand. All mixed solvent systems are reported as v/v solutions. All reactions were monitored by thin-layer chromatography (TLC), performed on Merck 60 (silica gel $\mathrm{F}_{254}$ ) plates. Chromatographic purification of products was accomplished using flash column chromatography on silica gel (230-400 mesh) purchased from Merck.

${ }^{1} \mathrm{H}$ - and ${ }^{13} \mathrm{C}-\mathrm{NMR}$ spectra were recorded in deuterated solvents on Bruker ARX 400 spectrometers and calibrated to the residual solvent peak. Chemical shifts $(\delta, \mathrm{ppm})$ are quoted relative to the residual solvent peak as internal standard and coupling constants $(J)$ are corrected and quoted to the nearest $0.1 \mathrm{~Hz}$. Multiplicities are abbreviated as follows: $\mathrm{s}=$ singlet, $\mathrm{d}=$ doublet, $\mathrm{t}=$ triplet, $\mathrm{m}=$ multiplet.

\section{Synthesis of the hydroxylamine linker}

\section{$O$-(4-Azidobutyl)hydroxylamine 4}

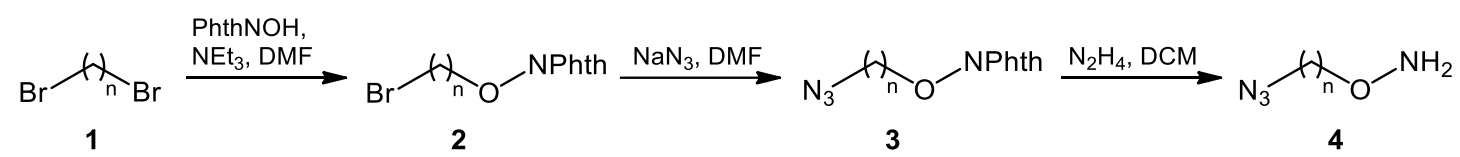

1,4-Dibromobutane 1 (5.9 mL, $49.4 \mathrm{mmol}, 2.0$ eq.) was added to a solution of $N$-hydroxyphthalimide (PhthNOH, $4.0 \mathrm{~g}, 24.5 \mathrm{mmol}, 1.0 \mathrm{eq}$.) and triethylamine (7.5 $\mathrm{mL}, 53.6 \mathrm{mmol}, 2.2$ eq.) in anhydrous dimethylformamide. The mixture was stirred at room temperature for $24 \mathrm{~h}$. The reaction was diluted with water, and the aqueous phase was extracted three times with ethyl acetate. The combined organic phases were dried over $\mathrm{MgSO}_{4}$, filtered and concentrated to give the crude product 2 (5.02 g, 16.9 mmol, 0.69 eq.) as a white solid. The residue was dissolved in anhydrous dimethylformamide and sodium azide (1.32 g, $20.6 \mathrm{mmol}, 0.85$ eq. $)$ was added. The mixture was stirred at room temperature for $2 \mathrm{~h}$, diluted with water and extracted with ethyl acetate three times. The combined organic phases were dried over $\mathrm{MgSO}_{4}$, filtered and concentrated. The crude was purified by flash chromatography on silica gel (iso-hexane/ethyl acetate $10: 1 \rightarrow 2: 1)$ to give $3(3.97 \mathrm{~g}, 15.2 \mathrm{mmol}, 0.62 \mathrm{eq}$.) as a yellow oil. The oil was redissolved in hydrazine monohydrate $(1.1 \mathrm{~mL}, 22.8 \mathrm{mmol}$, 0.93 eq.) and dichloromethane $(10 \mathrm{~mL})$. The mixture was stirred at room temperature for $24 \mathrm{~h}$ and then filtered. The solution was diluted with dichloromethane and washed with $\mathrm{NaCl}$ aq. three times. The combined organic phases were dried over $\mathrm{MgSO}_{4}$, 
filtered and concentrated to give $4(1.81 \mathrm{~g}, 13.9 \mathrm{mmol}, 57 \%$ yield over three steps $)$ as a colorless oil.

$\boldsymbol{R}_{\mathrm{f}}=0.42(\mathrm{DCM} / \mathrm{MeOH} 10: 1)$.

${ }^{1} \mathbf{H}-\mathbf{N M R}\left(400 \mathrm{MHz}, \mathrm{CDCl}_{3}\right): \delta=3.70\left(\mathrm{t},{ }^{3} \mathrm{~J}_{\mathrm{H}, \mathrm{H}}=5.6 \mathrm{~Hz}, 2 \mathrm{H}, \mathrm{O}-\mathbf{C H}_{\mathbf{2}}-\mathrm{CH}_{2}\right), 3.38(\mathrm{t}$, $\left.{ }^{3} J_{\mathrm{H}, \mathrm{H}}=6.4 \mathrm{~Hz}, 2 \mathrm{H}, \underline{\mathrm{CH}}_{2}-\mathrm{N}_{3}\right), 1.68-1.64\left(\mathrm{~m}, 4 \mathrm{H}, \mathrm{CH}_{2}-\mathrm{CH}_{2}-\mathrm{C}_{2}-\mathrm{CH}_{2}\right)$.

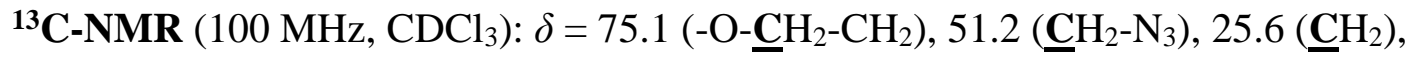
$25.5\left(\underline{\mathrm{CH}}_{2}\right)$.

HRMS (ESI+): calculated for $\mathrm{C}_{4} \mathrm{H}_{11} \mathrm{ON}_{4}{ }^{+}[\mathrm{M}+\mathrm{H}]^{+}: 131.0927$, found: 131.0928 .

\section{$O$-(4-Azidobutyl)- $N$-[(4-methoxyphenyl)diphenylmethyl]hydroxylamine (5)}<smiles>[14CH3][14CH2]NO[14C]N</smiles>

5

$O$-(4-Azidobutyl)hydroxylamine 4 (1.88 g, $14.4 \mathrm{mmol}, 1.0$ eq.) was dissolved in anhydrous dichloromethane (40 mL). 4-Monomethoxytritylchloride (MMTr-Cl, 4.91 $\mathrm{g}, 15.9 \mathrm{mmol}, 1.1 \mathrm{eq}$.) and diisopropylethylamine (5.0 mL, $28.9 \mathrm{mmol}, 2.0$ eq.) was added to the mixture at $0^{\circ} \mathrm{C}$. The reaction was stirred at room temperature for $2 \mathrm{~h}$, diluted with dichloromethane, washed with saturated $\mathrm{NaHCO}_{3}$, dried over $\mathrm{MgSO}_{4}$, filtered and concentrated. The crude was purified by flash chromatography on silica gel (iso-hexanes/ethyl acetate $15: 1+3 \%$ triethylamine) to give 5 (4.89 4g, $12.2 \mathrm{mmol}$, $84 \%)$ as a yellowish oil.

$\boldsymbol{R}_{\mathrm{f}}=0.64$ (iso-hexane/ ethyl acetate $10: 1+3 \%$ triethylamine).

${ }^{1} \mathbf{H}-\mathbf{N M R}\left(400 \mathrm{MHz}, \mathrm{CDCl}_{3}\right): \delta=7.31-7.18\left(\mathrm{~m}, 12 \mathrm{H}, 12 \times \mathrm{C}_{\mathrm{Ar}} \underline{\mathbf{H}}\right), 6.79\left(\mathrm{~d},{ }^{3} J_{\mathrm{H}, \mathrm{H}}=8.8\right.$ $\left.\mathrm{Hz}, 2 \mathrm{H}, 2 \times \mathrm{CH}_{3}-\mathrm{O}-\mathrm{C}-\mathrm{C} \underline{\mathbf{H}}\right), 3.76\left(\mathrm{~s}, 3 \mathrm{H}, \mathrm{O}-\mathbf{C H}_{3}\right), 3.65\left(\mathrm{t},{ }^{3} J_{\mathrm{H}, \mathrm{H}}=6.0 \mathrm{~Hz}, 2 \mathrm{H}\right.$, $\left.\mathrm{O}-\underline{C}_{2}-C_{2}\right), 3.05\left(\mathrm{t},{ }^{3} J_{\mathrm{H}, \mathrm{H}}=6.8 \mathrm{~Hz}, 2 \mathrm{H}, \mathrm{N}_{3}-\underline{C}_{2}\right), 1.52-1.37 \quad(\mathrm{~m}, 4 \mathrm{H}$, $\left.\mathrm{N}_{3}-\mathrm{CH}_{2}-\mathrm{CH}_{2}-\underline{\mathrm{C}}_{2}-\mathrm{CH}_{2}\right)$.

${ }^{13} \mathbf{C}$-NMR $\left(100 \mathrm{MHz}, \mathrm{CDCl}_{3}\right): \delta=158.3\left(\mathrm{CH}_{3}-\mathrm{O}-\underline{\mathbf{C}}\right), 144.6\left(2 \times \underline{\mathbf{C}}_{\mathrm{Ar}}\right), 136.6\left(\underline{\mathbf{C}}_{\mathrm{Ar}}\right)$, $130.2\left(2 \times \underline{\mathbf{C}}_{\mathrm{Ar}}\right), 129.0(4 \times \underline{\mathbf{C}} \underline{\mathrm{Ar}}), 127.6(4 \times \underline{\mathbf{C}} \underline{\mathrm{Ar}}), 126.7\left(2 \times \underline{\mathbf{C}}_{\mathrm{Ar}}\right), 112.9\left(2 \times \underline{\mathbf{C}}_{\mathrm{Ar}}\right)$, $77.2(\mathrm{O}-\mathrm{NH}-\underline{\mathbf{C}}), 73.2\left(\mathrm{O}-\underline{\mathbf{C}} \mathrm{H}_{2}\right), 55.2\left(\mathrm{O}-\underline{\mathbf{C}} \mathrm{H}_{3}\right), 51.1\left(\mathrm{~N}_{3}-\underline{\mathbf{C H}}_{2}\right), 25.8\left(\mathrm{~N}_{3}-\mathrm{CH}_{2}-\underline{\mathbf{C}} \mathrm{H}_{2}\right)$, $25.5\left(\mathrm{O}-\mathrm{CH}_{2}-\underline{\mathrm{CH}_{2}}\right)$.

HRMS (ESI-): calculated for $\mathrm{C}_{25} \mathrm{H}_{27} \mathrm{O}_{4} \mathrm{~N}_{4}{ }^{-}\left[\mathrm{M}+\mathrm{HCO}_{2}\right]^{-}$: 447.2038, found: 447.2040. 


\section{3. ${ }^{1} \mathrm{H}-\mathrm{NMR}$ spectra of the linker}
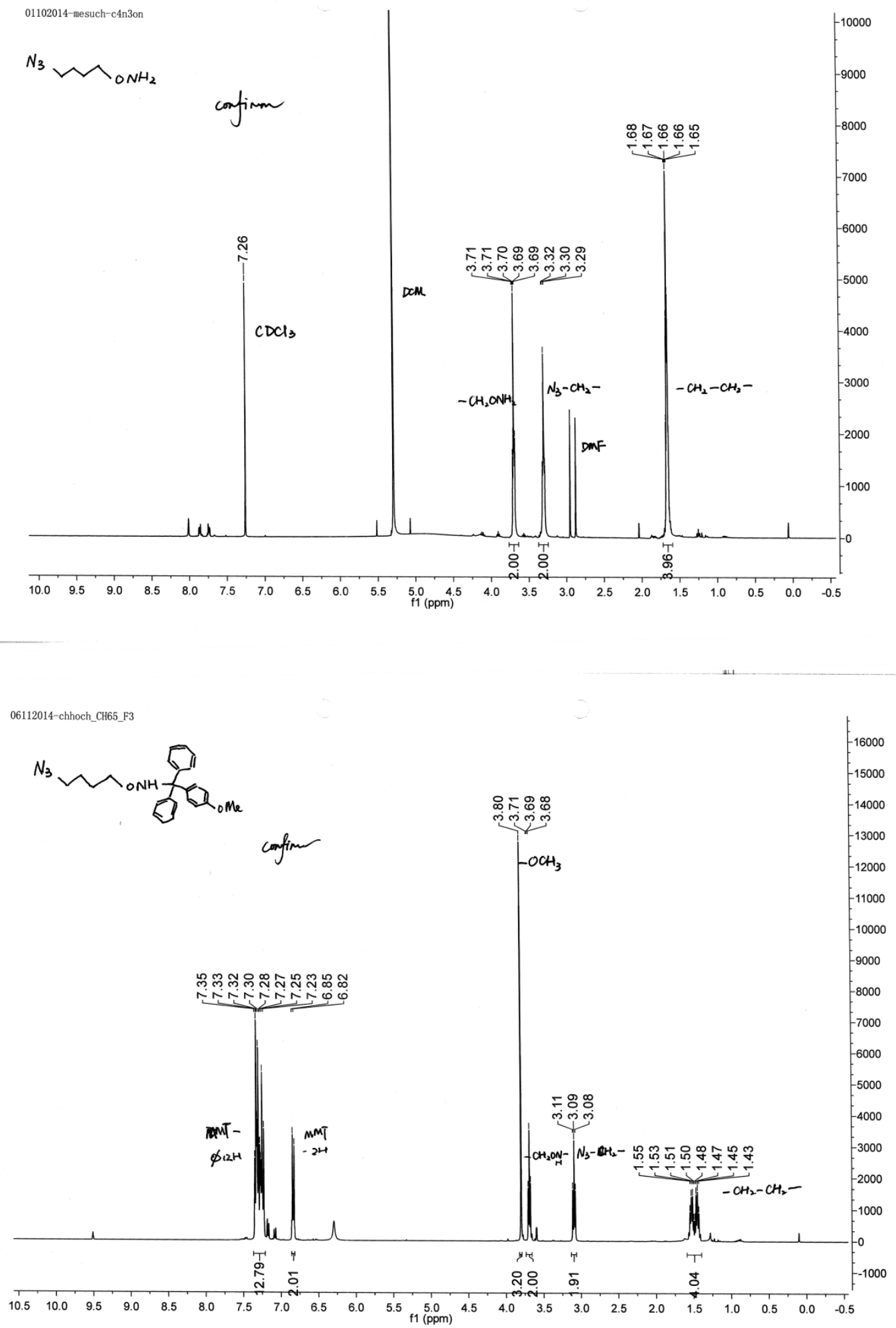


\section{General methods for oligonucleotide synthesis}

DNA Oligonucleotide synthesis was performed on an Applied Biosystems Incorporated 394 automated synthesizer. Phosphoramidites and solid supports columns were purchased from Glen Research, Link Technology, and ChemGene Corporation. Oligodeoxynucleotides were synthesized in a $1 \mu \mathrm{mol}$ scale with standard DNA synthesis cycles (trityl off mode). Coupling time for modified nucleosides was extended to $10 \mathrm{~min}$. The oligonucleotide was cleaved using conc. ammonium hydroxide aq. at $25^{\circ} \mathrm{C}$ for $17 \mathrm{~h}$. The aqueous solution was then collected and evaporated in a SpeedVac concentrator, and the pellet was redissolved in $\mathrm{ddH}_{2} \mathrm{O}$.

Analytical RP-HPLC was performed using a Macherey-Nagel Nucleodur 100-3 C18ec column on 2695 Separation Module equipped with a Waters Alliance 2996 Photodiode Array Detector using a flow of $0.5 \mathrm{~mL} / \mathrm{min}$. Semi-preparative RP-HPLC was performed using a Macherey-Nagel C18 column $(5 \mathrm{~mm}, 9.4 \times 250 \mathrm{~mm})$ on Waters Breeze 2487 Dual $\lambda$ Array Detector, 1525 Binary HPLC Pump. Conditions: Buffer A, 0.1 M TEAA (triethylammonium acetate) in water; buffer B, 0.1 M TEAA in $80 \%$ acetonitrile.

The purified fractions were concentrated and characterized by Matrix Assisted Laser Desorption Ionization Time of Flight (MALDI-TOF) on a Bruker Daltonics Autoflex II instrument. The concentration of the oligonucleotide solutions was calculated from the UV absorbance at $260 \mathrm{~nm}$ on a Nanodrop ND-1000 spectrophotometer. Extinction coefficients of the oligonucleotides at $260 \mathrm{~nm}$ were calculated by addition of the extinction coefficients of the individual nucleobases: dA $15.0 \mathrm{~L} /(\mathrm{mmol} \cdot \mathrm{cm}), \mathrm{dC} 7.1$ $\mathrm{L} /(\mathrm{mmol} \cdot \mathrm{cm}), \mathrm{dG} 12.0 \mathrm{~L} /(\mathrm{mmol} \cdot \mathrm{cm}), \mathrm{dT} 8.4 \mathrm{~L} /(\mathrm{mmol} \cdot \mathrm{cm}), \mathrm{mdC} 7.8 \mathrm{~L} /(\mathrm{mmol} \cdot \mathrm{cm})$, hmdC $8.7 \mathrm{~L} /(\mathrm{mmol} \cdot \mathrm{cm})$, fdC $11.3 \mathrm{~L} /(\mathrm{mmol} \cdot \mathrm{cm})$, cadC $7.1 \mathrm{~L} /(\mathrm{mmol} \cdot \mathrm{cm})$. The 1,2,3-triazole and abasic monomer are transparent at $260 \mathrm{~nm}$.

\section{Click reaction on the solid support with azide linkers and deprotection}

After solid phase synthesis $(0.2 \mu \mathrm{mol}$ scale, approx. 50\% yield for 13 mer, calculated as $0.1 \mu \mathrm{mol})$, the solid support was suspended in dimethyl sulfoxide $(80 \mu \mathrm{L})$ and acetonitrile $(25 \mu \mathrm{L})$. To the mixture, $\mathrm{CuSO}_{4}$ aq. (100 mM, $50 \mu \mathrm{L}, 5.0 \mu \mathrm{mol}, 50$ eq.), sodium ascorbate aq. (500 mM, $20 \mu \mathrm{L}, 10 \mu \mathrm{mol}, 100$ eq.), $N, N$-diisopropylethylamine solution in acetonitrile ( $200 \mathrm{mM}, 75 \mu \mathrm{L}, 15 \mu \mathrm{mol}, 150$ eq.), solution of $\mathbf{5}$ in dimethyl sulfoxide ( $100 \mathrm{mM}, 50 \mu \mathrm{L}, 5.0 \mu \mathrm{mol}, 50$ eq.) were added. The reaction was conducted at $25{ }^{\circ} \mathrm{C}$ for $24 \mathrm{~h}$. Afterwards, the solid support was washed with dimethyl sulfoxide, dilute $\mathrm{NaHCO}_{3}$ aq., acetonitrile, ether and air-dried to a powder. The solid phase was then cleaved with conc. aqueous $\mathrm{NH}_{3}$ at $25^{\circ} \mathrm{C}$ for $17 \mathrm{~h}$, purified by HPLC and concentrated. The removal of the MMTr protection group on the hydroxylamine was carried out by dissolving the obtained oligonucleotide in acetic acid aq. (20\%, $200 \mu \mathrm{L})$ at $25{ }^{\circ} \mathrm{C}$ for $30 \mathrm{~min}$, precipitated by addition of sodium acetate solution $(3 \mathrm{M}, 60 \mu \mathrm{L})$ and $\mathrm{EtOH}(1040 \mu \mathrm{L})$, and then purified again with HPLC. 


\section{Schiff base formation between fdC-oligonucleotides and probe strands}

A mixture of $\mathrm{fdC}$ containing oligonucleotides $(\mathbf{T 1}, \mathbf{2})$, or $\mathrm{T} / \mathrm{C} / \mathrm{mC} / \mathrm{hmC} / \mathrm{caC} / \mathrm{Abasic}$ containing oligonucleotides (T3-8) in control experiments $(15 \mu \mathrm{M}, 20 \mu \mathrm{L}, 0.3 \mathrm{nmol}, 1$ eq.), probe strands ( $15 \mu \mathrm{M}, 20 \mu \mathrm{L}, 0.3$ nmol, 1 eq.), $\mathrm{NaCl}$ aq. (1 M, $15 \mu \mathrm{L}), \mathrm{NaOAc}$ aq. $(\mathrm{pH}=6.0,100 \mathrm{mM}, 15 \mu \mathrm{L})$ and $\mathrm{ddH}_{2} \mathrm{O}(80 \mu \mathrm{L})$ was prepared to make a final volume of $150 \mu \mathrm{L}$ (oligonucleotide working concentration $2 \mu \mathrm{M}$ ). The mixture was heated to $85{ }^{\circ} \mathrm{C}$ for $5 \mathrm{~min}$ then slowly cooled down to $25^{\circ} \mathrm{C}$ in $3 \mathrm{~h}$. A first aliquot $(15$ $\mu \mathrm{L})$ was taken and quenched before $5.4 \mu \mathrm{L}$ of 4-methoxyaniline solution $(250 \mathrm{mM}$, $\mathrm{ddH}_{2} \mathrm{O} / \mathrm{DMSO}, \mathrm{v} / \mathrm{v} 9 / 1$, acidified to $\mathrm{pH}=5.5$ with acetate acid) was added to give a catalyst working concentration of $10 \mathrm{mM}$. The reaction was conducted at $25{ }^{\circ} \mathrm{C}, 500$ rpm for $24 \mathrm{~h}$. Aliquots $(15 \mu \mathrm{L})$ were taken at 1, 2, 4, 6, 8, 12, $24 \mathrm{~h}$ and quenched by addition of loading buffer. All the samples were heated at $85^{\circ} \mathrm{C}$ for 3 min followed by PAGE assay as mentioned above.

When using 1,4-benzenediamine as the catalyst, a $10 \mathrm{mM}$ stock solution of $10 \mathrm{mM}$ in $0.5 \%$ acetic acid aq. was prepared.

\section{Melting point experiments}

Melting profiles were measured on a JASCO V-650 spectrometer using quartz glass cuvettes with $10 \mathrm{~mm}$ path length. The samples contained $100 \mathrm{mM} \mathrm{NaCl}, 10 \mathrm{mM}$ NaOAc buffer pH 6.0 and $1 \mu \mathrm{M}$ of each strand in a final volume of $200 \mu \mathrm{L}$. The measurement was repeated three times with independent sample. Before the measurement, the oligonucleotides were hybridized by slowly cooling down the samples from $85^{\circ} \mathrm{C}$ to room temperature. The solutions were covered with silicon oil and tightly plugged. Absorbance was recorded in the forward and reverse direction at temperatures from $25{ }^{\circ} \mathrm{C}$ (or $15{ }^{\circ} \mathrm{C}$ ) to $85^{\circ} \mathrm{C}$ with a slope of $1{ }^{\circ} \mathrm{C} / \mathrm{min}$. $\mathrm{T}_{\mathrm{M}}$ values were calculated as the zero-crossing of $2^{\text {nd }}$ derivate of the $339 \mathrm{~nm}$ background corrected change in hyperchromicity at $260 \mathrm{~nm}$. 
Table S1. Synthesized oligonucleotides in this study. (Letters in bold and italic stand for 2'-O-propargyl nucleosides or epigenetic modifications.)

\begin{tabular}{cllcc}
\hline Entry & Description & 5'----------3' & Calc. & Exptl. \\
\hline T1 & ODN-fC & GTAATGfCGCTAGG & 4040.9 & 4036.2 \\
T2 & fC-shift & GTAATfCCGCTAGG & 4000.9 & 3999.6 \\
T3 & fC-T & GTAATGTGCTAGG & 4027.7 & 4024.7 \\
T4 & fC-C & GTAATGCGCTAGG & 4012.7 & 4008.6 \\
T5 & fC-mC & GTAATGmCGCTAGG & 4026.7 & 4021.6 \\
T6 & fC-hmC & GTAATGhmCGCTAGG & 4042.7 & 4039.6 \\
T7 & fC-caC & GTAATGcaCGCTAGG & 4056.7 & 4054.9 \\
T8 & fC-Abasic & GTAATGAPGCTAGG & 3919.6 & 3916.4 \\
\hline & Probe-1-alkyne & CCUAGCGCATTAC & 3932.7 & 3930.5 \\
P1 & Probe-1-MMTr & CCUAGCGCATTAC & 4335.2 & 4335.1 \\
& Probe-1-ONH2 & CCU*AGCGCATTAC & $4084.8^{[a]}$ & 4084.2 \\
& Probe-2-MMTr & CCUATCGCATTAC & 4310.2 & 4310.3 \\
P2 & Probe-2-ONH 2 & CCU*ATCGCATTAC & $4059.8^{[a]}$ & 4064.3 \\
\hline
\end{tabular}

[a] contains one sodium ion 

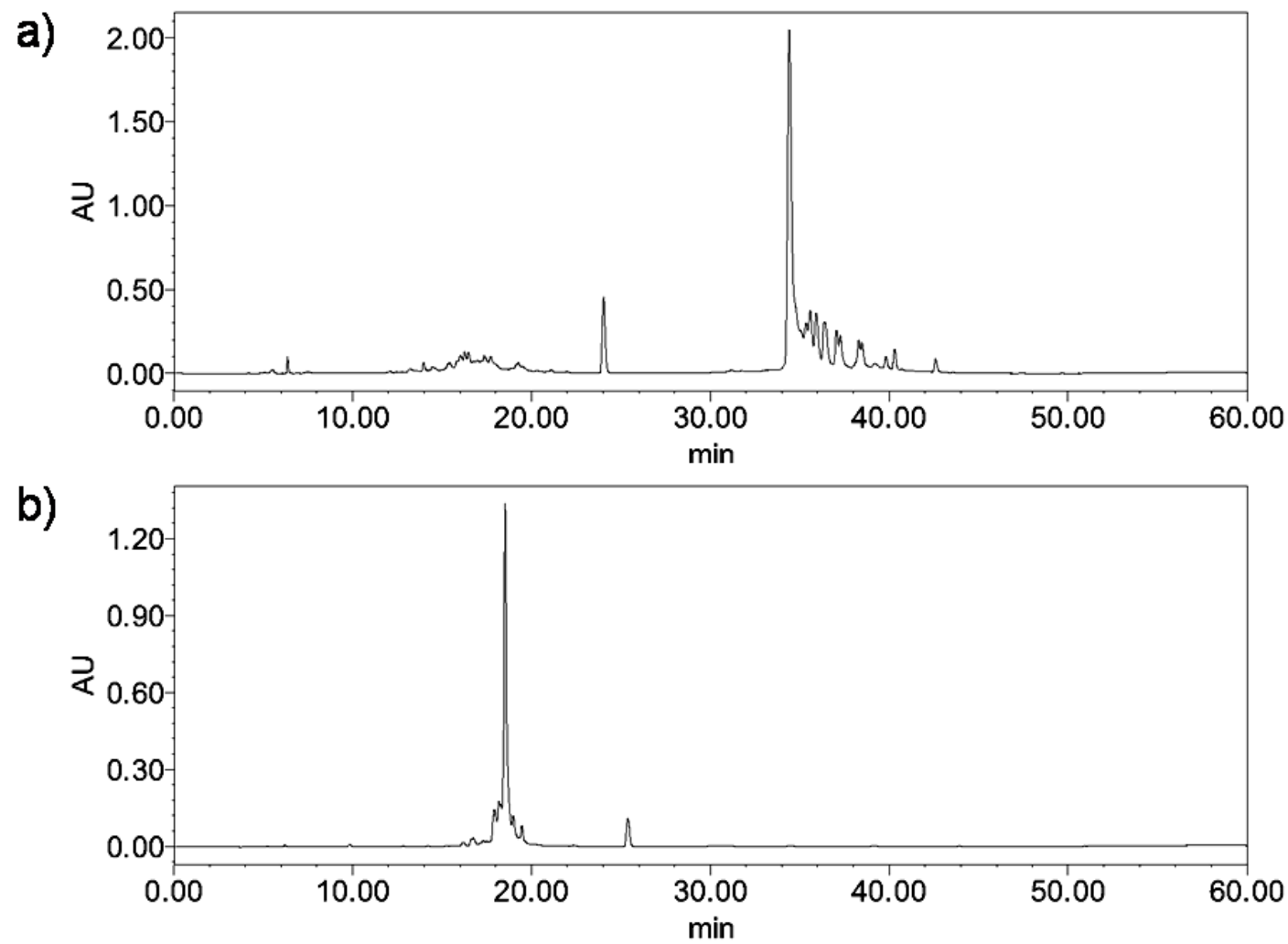

Figure S1. Typical HPLC trace of crude product a) P1-MMTr and b) P1-ONH2. Conditions: buffer A, 0.1 M TEAA; buffer B, 0.1 M TEAA in $80 \%$ acetonitrile, linear gradient from $0 \%$ to $60 \%$ B over $45 \mathrm{~min}$. Retation time: (a) $34.4 \mathrm{~min}$, (b) $18.5 \mathrm{~min}$. $\mathrm{AU}=$ arbitrary unit. 


\section{Crosslinking studies with the synthesized strands}
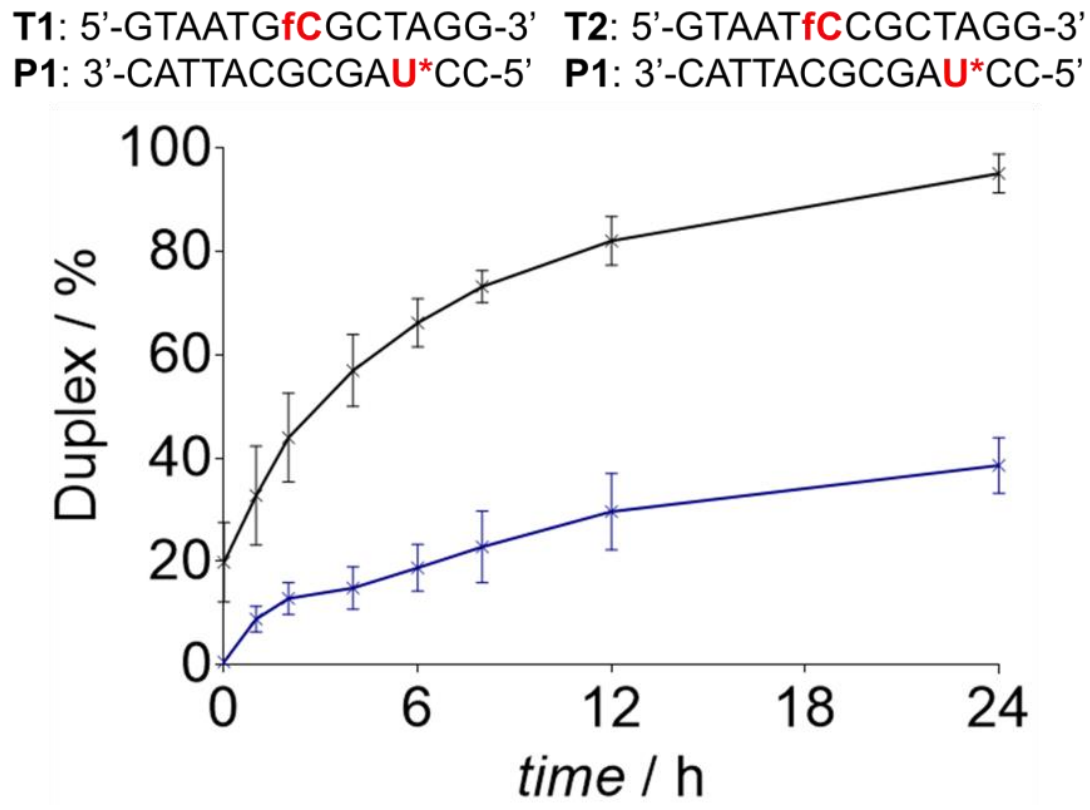

Figure S2. Quantification of the DNA duplex formation during the reaction using the catalyst 4-methoxyaniline. Black line: duplex formation between T1 and P1, blue line: duplex formation between T2 and P1. Error bars represent the standard error of the mean calculated from three replicates.

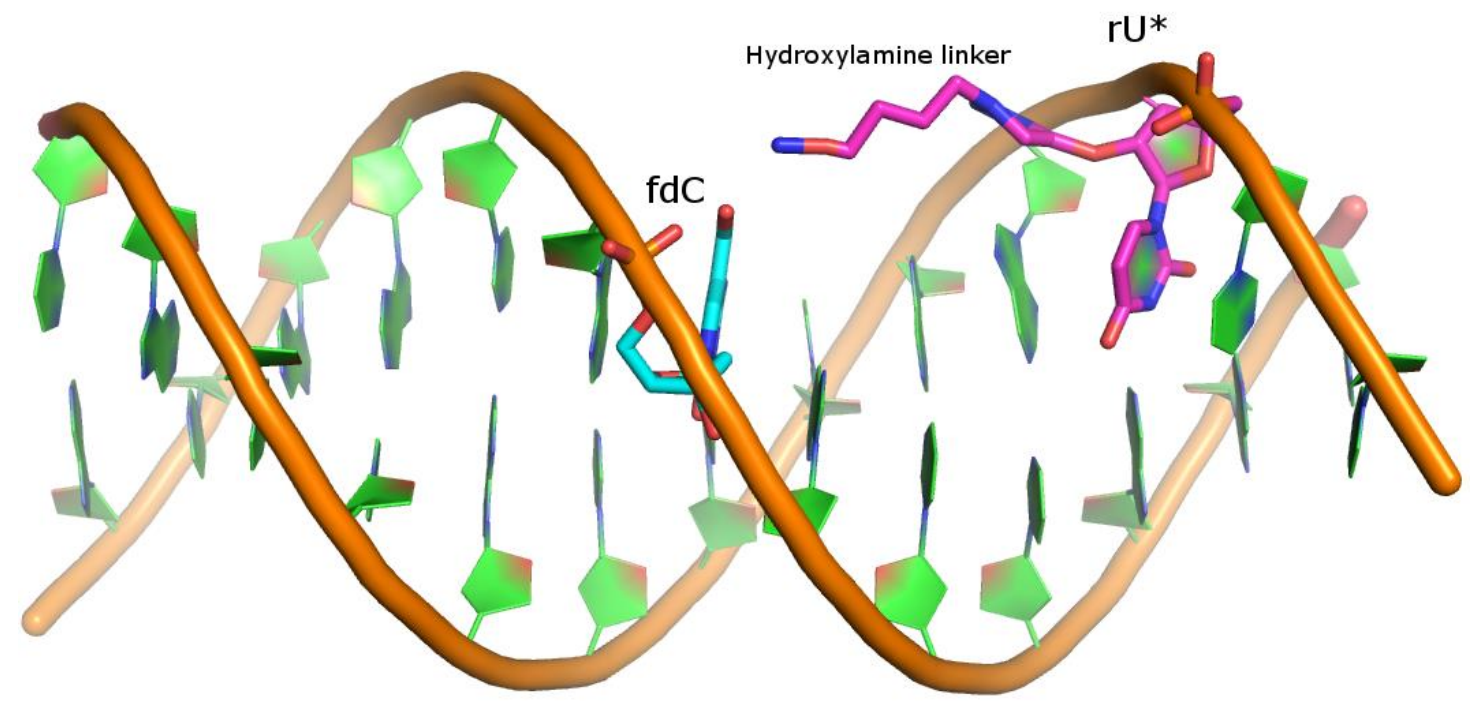

Figure S3. Model representation of a duplex showing the position of the hydroxylamine linker relative to the $\mathrm{fdC}$ on the complementary strand. 

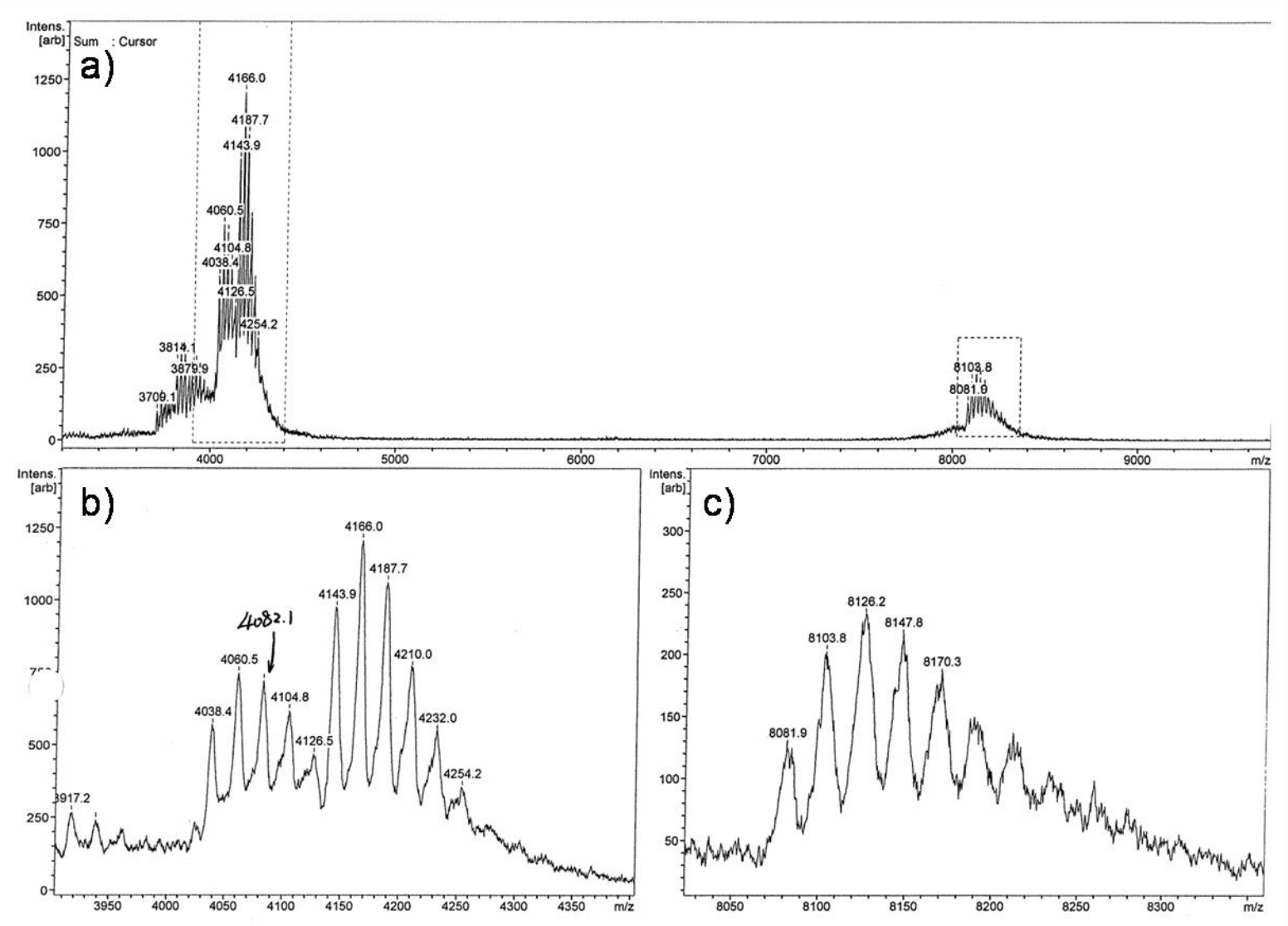

\begin{tabular}{cccc}
\hline No. & 5'-----------3' & Calc. & Exptl. \\
\hline P1 & CCU*AGCGCATTAC & 4061.8 & 4060.5 \\
T1 & GTAATGfCGCTAGG & 4040.9 & 4038.4 \\
T1 & GTAATGfCGCTAGG & $4146.0^{[a]}$ & 4143.9 \\
T1:P1 & & 8084.7 & 8081.9 \\
\hline
\end{tabular}

[a] conjugate with 4-methoxyaniline

Figure S4. MALDI-TOF mass spectrum of the crosslinked duplex T1:P1 and single strands. a) Overall MALDI-TOF spectrum; b) peaks corresponding to single strands P1 and P1- 4-methoxyaniline conjugate; c) peaks corresponding to linked duplex T1:P1. Conditions: $10 \mu \mathrm{M}$ oligonucleotides, $100 \mathrm{mM} \mathrm{NaCl}, 10 \mathrm{mM} \mathrm{NaOAc}$ buffer $\mathrm{pH} 6.0$. 


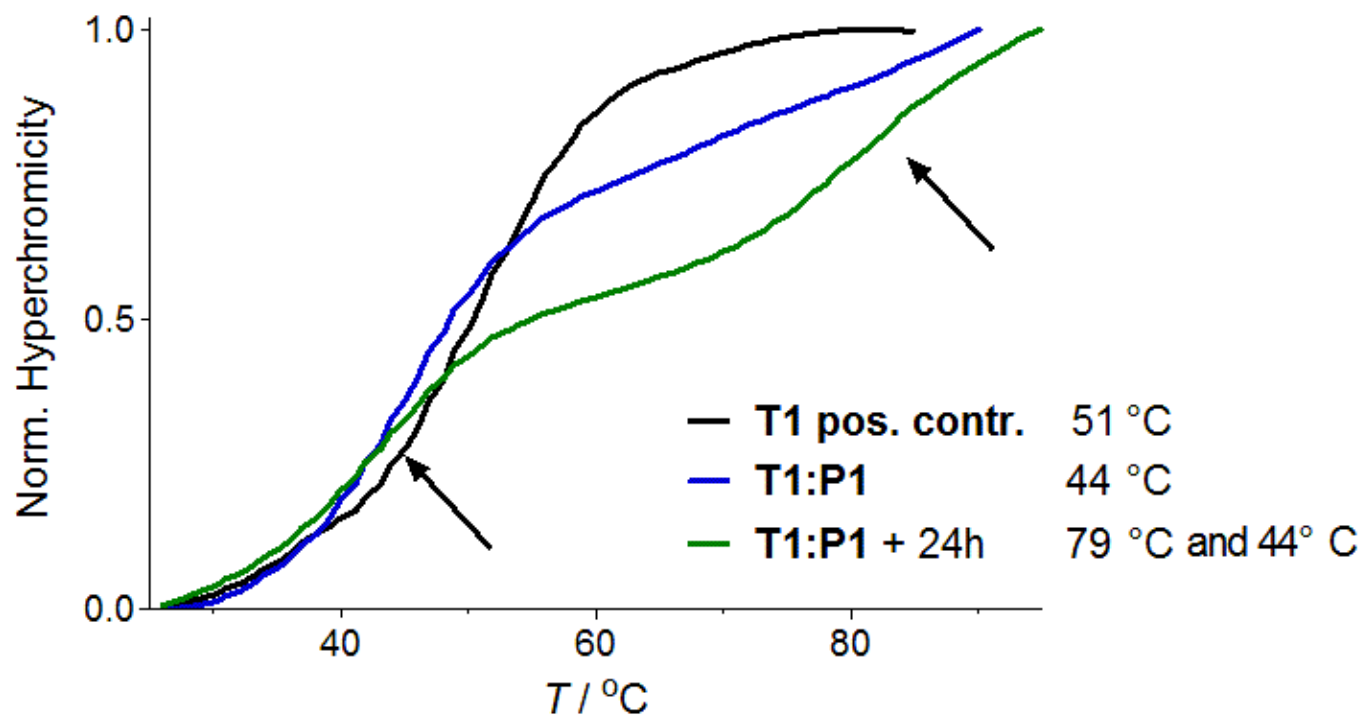

Figure S5. Melting curves of duplex T1:P1 after reannealing or after $24 \mathrm{~h}$ incubation without catalyst compared with duplex $\mathbf{T 1}$ and its counter strand (positive control). Conditions: $1 \mu \mathrm{M}$ oligonucleotides, $100 \mathrm{mM} \mathrm{NaCl}, 10 \mathrm{mM}$ NaOAc buffer $\mathrm{pH}$ 6.0, the final volume of $200 \mu \mathrm{L}$. 


\section{Experimental details of the genomic fdC profiling study}

\section{Cell culture and genomic DNA isolation}

J1 wild type stem cells (strain 129/SvJae), ${ }^{[1]}$ Dnmt TKO (J1, strain 129/SvJae), ${ }^{[2]}$ $\mathrm{Tdg}^{+-}$(E14, strain 129/Ola) and the $\mathrm{Tdg}^{-/-}$cell line (E14, strain 129/Ola), ${ }^{[3]}$ were routinely maintained on gelatinized plates in DMEM (Sigma-Aldrich) supplemented with 10\% FBS (PAN Biotech), 1x MEM-nonessential amino acids (NEAA), $0.2 \mathrm{mM}$ L-alanyl-L-glutamine, 1x penicillin-streptomycin, $0.1 \mathrm{mM} ß$-mercaptoethanol (all from Sigma-Aldrich), $1000 \mathrm{U} / \mathrm{ml}$ mouse recombinant LIF (ORF Genetics), $1 \mu \mathrm{M}$ PD 0325901 and $3 \mu \mathrm{M}$ CHIR 99021 (2i; both from Axon Medchem). In these conditions, global genomic $\mathrm{mC}$ levels are very low and its oxidized derivatives are even lower, as we described previously. ${ }^{[4]}$ For the experiments, the cultures were passaged twice (over five days), in DMEM supplemented with FBS and LIF, but lacking 2i. With this strategy, primed mESC cultures were obtained and oxidized cytosine derivatives reached reproducibly higher and stable levels. ${ }^{[4]}$ In case of the experiment using J1 wild type and Dnmt TKO cells, the cultures were passaged every second day over a period of six days.

Mouse embryonic stem cells were lysed directly in the plates with RLT-buffer (Qiagen). The lysates were homogenized with a TissueLyser MM400 (Retsch) for $1 \mathrm{~min}$ at $30 \mathrm{~Hz}$ and centrifuged for $5 \mathrm{~min}$ at $21000 \mathrm{xg}$. Then genomic DNA was isolated using the Zymo Quick gDNA Midi Kit according to the manufacturer's instruction. The concentration was measured using a Nanodrop ND-1000 (Peqlab).

\section{Probe crosslinking}

The gDNA solution obtained above $(1.2 \mu \mathrm{g})$, the fdC probe $(\mathbf{P})(1 \mu \mathrm{M}, 2 \mu \mathrm{L})$, $\mathrm{NaH}_{2} \mathrm{PO}_{4}-\mathrm{Na}_{2} \mathrm{HPO}_{4}$ buffer $(200 \mathrm{mM}, \mathrm{pH}=6.0,2 \mu \mathrm{L}), \mathrm{NaCl}$ aq. $(1.5 \mathrm{M}, 2 \mu \mathrm{L})$, and $\mathrm{ddH}_{2} \mathrm{O}$ were mixed to a final volume of $18 \mu \mathrm{L}$. The mixture was heated to $95{ }^{\circ} \mathrm{C}$ for 3 min, and then cooled down rapidly to $25^{\circ} \mathrm{C}$. 1,4-Benzenediamine aq. (10 mM, $\left.2 \mu \mathrm{L}\right)$ was added and the reaction vial shaken $(300 \mathrm{rpm})$ for $6 \mathrm{~h}$ at $25^{\circ} \mathrm{C}$. First, the mixture was neutralized with $\mathrm{Na}_{2} \mathrm{HPO}_{4}$ aq. $(200 \mathrm{mM}, 40 \mu \mathrm{L})$, and then purification with $N E B$ Monarch PCR DNA Cleanup Kit using the binding buffer $(120 \mu \mathrm{L})$ and eluting with the elution buffer (Tris-EDTA) $(30 \mu \mathrm{L})$. The eluted solution was quantified with the Nanodrop and 22-32 $\mathrm{ng} / \mu \mathrm{L}$ was obtained. UV spectra confirmed the main peak centered at $260 \mathrm{~nm}$. 


\section{Ligation}

The crosslinked gDNA solution (300 ng), reporter strand $(\mathbf{R})(20 \mathrm{nM}, 1 \mu \mathrm{L})$, Ampligase reaction buffer $(10 \times, 2 \mu \mathrm{L})$, Ampligase from Epicenter $(5 \mathrm{U} / \mu \mathrm{L}, 2 \mu \mathrm{L}, 10$ $\mathrm{U})$ and $\mathrm{ddH}_{2} \mathrm{O}$ were mixed to a final volume of $20 \mu \mathrm{L}$. The mixture was heated to $95{ }^{\circ} \mathrm{C}$ for $3 \mathrm{~min}$, and then to $94{ }^{\circ} \mathrm{C}$ for $1 \mathrm{~min}, 60{ }^{\circ} \mathrm{C}$ for $1 \mathrm{~h}$ and back to $94{ }^{\circ} \mathrm{C}$ for 10 cycles. Then, the reaction mixture was diluted with Tris- $\mathrm{HCl}$ buffer $(200 \mathrm{mM}, \mathrm{pH}=$ 7.6, $50 \mu \mathrm{L}$ ) before purification with NEB Monarch PCR DNA Cleanup Kit using the binding buffer $(140 \mu \mathrm{L})$ and eluting with the elution buffer $(10 \mu \mathrm{L})$. The eluted solution was quantified with the Nanodrop, obtaining 20-32 ng/ $\mu \mathrm{L}$. UV spectra confirmed the main peak centered at $260 \mathrm{~nm}$.

\section{Droplet digital PCR}

ddPCR experiments were performed on a Bio-Rad QX100 ddPCR System. For one reaction, gDNA (6 ng), four primers $(18 \mu \mathrm{M}$ each, $1 \mu \mathrm{L})$, two TaqMan probes $(5 \mu \mathrm{M}$ each, $1 \mu \mathrm{L}$ ), digital PCR Supermix for Probes (no dUTP, $2 \times, 10 \mu \mathrm{L}$ ), and $\mathrm{ddH}_{2} \mathrm{O}$ were mixed to a final volume of $20 \mu \mathrm{L}$ with primer working concentration of $900 \mathrm{nM}$ and TaqMan probe working concentration of $250 \mathrm{nM}$.

PCR cycles were conducted on a Bio-Rad T100 Thermal cycler. PCR cycle: $95^{\circ} \mathrm{C}$ for $10 \mathrm{~min}, 94^{\circ} \mathrm{C}$ for $30 \mathrm{sec}$ and specific annealing temperature $\left(64^{\circ} \mathrm{C}\right)$ for $1 \mathrm{~min}$ for 35 or 40 cycles, then $98^{\circ} \mathrm{C}$ for $10 \mathrm{~min}$ and cooled down to $12^{\circ} \mathrm{C}$. A temperature ramp of $2{ }^{\circ} \mathrm{C} / \mathrm{s}$ was used. Droplet generation and counting were conducted according to the manufacturer's instructions, i.e. reaction mixture prepared as above $(20 \mu \mathrm{L})$ and ddPCR droplet generate oil $(70 \mu \mathrm{L})$ were used per reaction. The accounted droplet number was retained in 10000-18000. FAM for detection amplicon was set to channel 1; HEX for reference amplicon was set to channel 2.

Each percentage value represents the averages and standard deviations from the mean of at least two technical replicates and two biological replicates. LC-MS quantification were conducted according to the previous report. ${ }^{[5]}$

\section{References}

[1] E. Li, T. H. Bestor, R. Jaenisch, Cell 1992, 69, 915-926.

[2] A. Tsumura, T. Hayakawa, Y. Kumaki, S. Takebayashi, M. Sakaue, C. Matsuoka, K. Shimotohno, F. Ishikawa, E. Li, H. R. Ueda, J. Nakayama, M. Okano, Genes Cells 2006, $11,805-814$.

[3] D. Cortazar, C. Kunz, J. Selfridge, T. Lettieri, Y. Saito, E. MacDougall, A. Wirz, D. Schuermann, A. L. Jacobs, F. Siegrist, R. Steinacher, J. Jiricny, A. Bird, P. Schar, Nature 2011, 470, 419-423. 
[4] T. Pfaffeneder, F. Spada, M. Wagner, C. Brandmayr, S. K. Laube, D. Eisen, M. Truss, J. Steinbacher, B. Hackner, O. Kotljarova, D. Schuermann, S. Michalakis, O. Kosmatchev, S. Schiesser, B. Steigenberger, N. Raddaoui, G. Kashiwazaki, U. Muller, C. G. Spruijt, M. Vermeulen, H. Leonhardt, P. Schar, M. Muller, T. Carell, Nat Chem Biol 2014, 10, 574-581.

[5] M. Wagner, J. Steinbacher, T. F. J. Kraus, S. Michalakis, B. Hackner, T. Pfaffeneder, A. Perera, M. Müller, A. Giese, H. A. Kretzschmar, T. Carell, Angew. Chem., Int. Ed. 2015, $54,12511-12514$.

a)

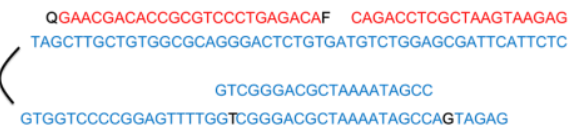
GTCGTGGTCATCTCC 法 ССTCCGACCTGAGTTCGTGATTTTGATCCTCGGTCGGTCCCCGGAG GGCTGGACTCAAGCAACTAA TTAGCCAGTAGAGGTTIGATTTGGCH TAGACTCCTGTCTCCACACA

b)

\begin{tabular}{|c|c|c|c|}
\hline Entry & Description & $5^{\prime}$ & mer \\
\hline P2 & probe for locus 1 & GAGATG*ACCGATAAAATCGCAGGGC & 25 \\
\hline R1 & report strand for locus 1 & $\begin{array}{l}\text { pTGGTITGAGGCCCCTGGTGTAGCTTGCTGTGGCG } \\
\text { CAGGGACTCTGTGATGTCTGGAGCGATTCATTCTC }\end{array}$ & 70 \\
\hline \multirow{6}{*}{ locus 1} & detection forward primer & CCGATAAAATCGCAGGGCTG & 20 \\
\hline & detection reverse primer & GAGAATGAATCGCTCCAGAC & 20 \\
\hline & detection TaqMan probe & F-ACAGAGTCCCTGCGCCACAGCAAG-Q & 24 \\
\hline & reference forward primer & GGCTGGACTCAAGCAACTAA & 20 \\
\hline & reference reverse primer & ACACACCTCTGTCCTCAGAT & 20 \\
\hline & reference TaqMan probe & H-CGGTITAGTITGGAGATGACCGAT-Q & 24 \\
\hline P3 & probe for locus 2 & 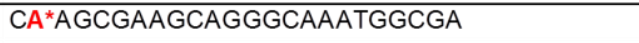 & 24 \\
\hline R2 & report strand for locus 2 & $\begin{array}{l}\text { pTCTCGAACCTCTGCCAGCCTAGCTTGCTGTGGCGC } \\
\text { AGGGACTCTGTGATGTCTGGAGCGATTCATTCTC }\end{array}$ & 69 \\
\hline \multirow{6}{*}{ locus 2} & detection forward primer & AAGCAGGGCAAATGGCGA & 19 \\
\hline & detection reverse primer & GAGAATGAATCGCTCCAGAC & 20 \\
\hline & detection TaqMan probe & F-ACAGAGTCCCTGCGCCACAGCAAG-Q & 24 \\
\hline & reference forward primer & CCAGGGAGCATCTGTGAAAA & 20 \\
\hline & reference reverse primer & AAAAGCCCATCTGGGAAACA & 20 \\
\hline & reference TaqMan probe & H-CCCCTTCAGACGCAAGCGAAGCAG-Q & 24 \\
\hline
\end{tabular}

Figure S6. Sequence detail of the detection strategy: a) Illustration of the detection strategy with sequence details for locus 1 , i.e. $30,020,539^{\text {th }}$ position on chromosome 16 (MM9); b) synthesized and purchased oligonucleotides for locus 1 and 2. Bold and red letters represent nucleoside modifications or functional group: $\mathrm{p}$, phosphate group at 5' terminus; F, FAM; H, HEX; Q, BHQ-1. MALDI-TOF: P2: calc.7951.5, found 7948.5, P3 calc. 7672.5, found 7671.0, contain one sodium ion. 


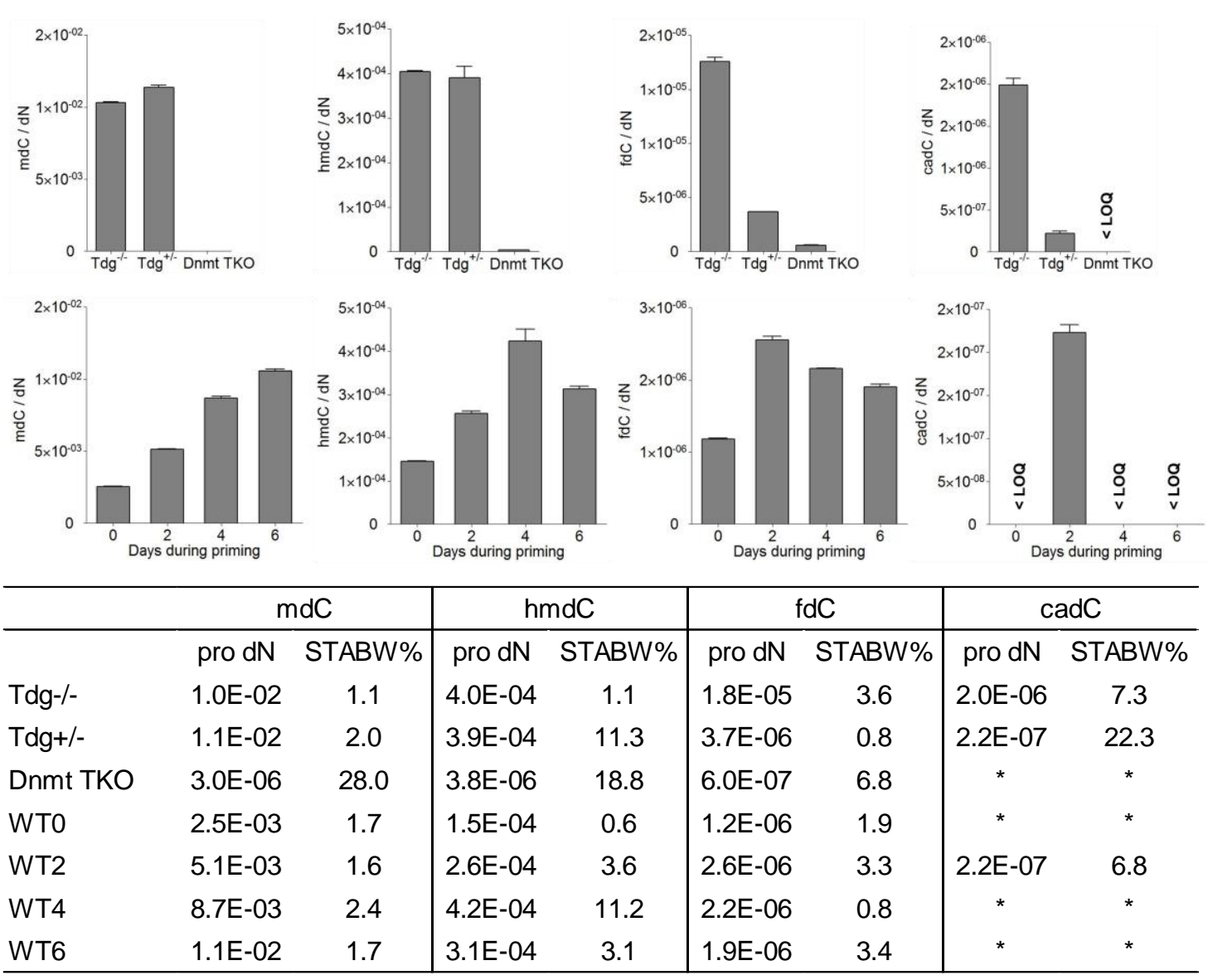

Figure S7. Global $5 \mathrm{mC}, 5 \mathrm{hmC}$, fdC, and $5 \mathrm{caC}$ quantification using LC-MS: $\mathrm{Tdg}^{-/-}$, $\mathrm{Tdg}^{+-}$, and Dnmt TKO mES cells and 0, 2, 4, 6 days during priming of wild-type mES cells. *: $<\mathrm{LOQ}$, below the limit of quantification. 
a)

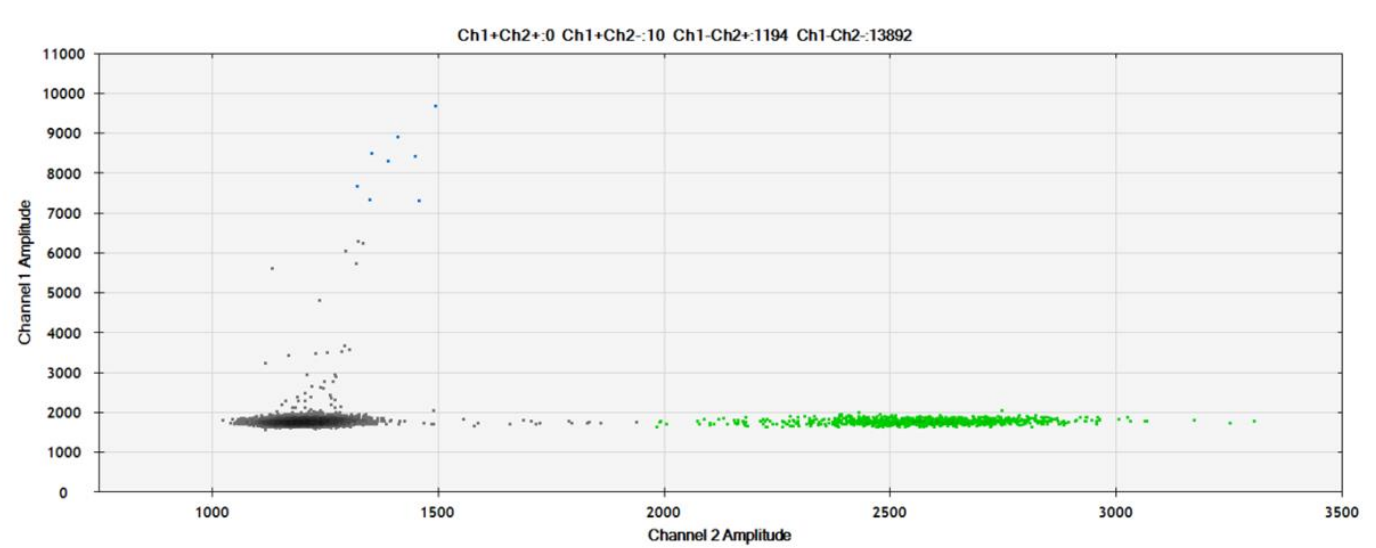

b)

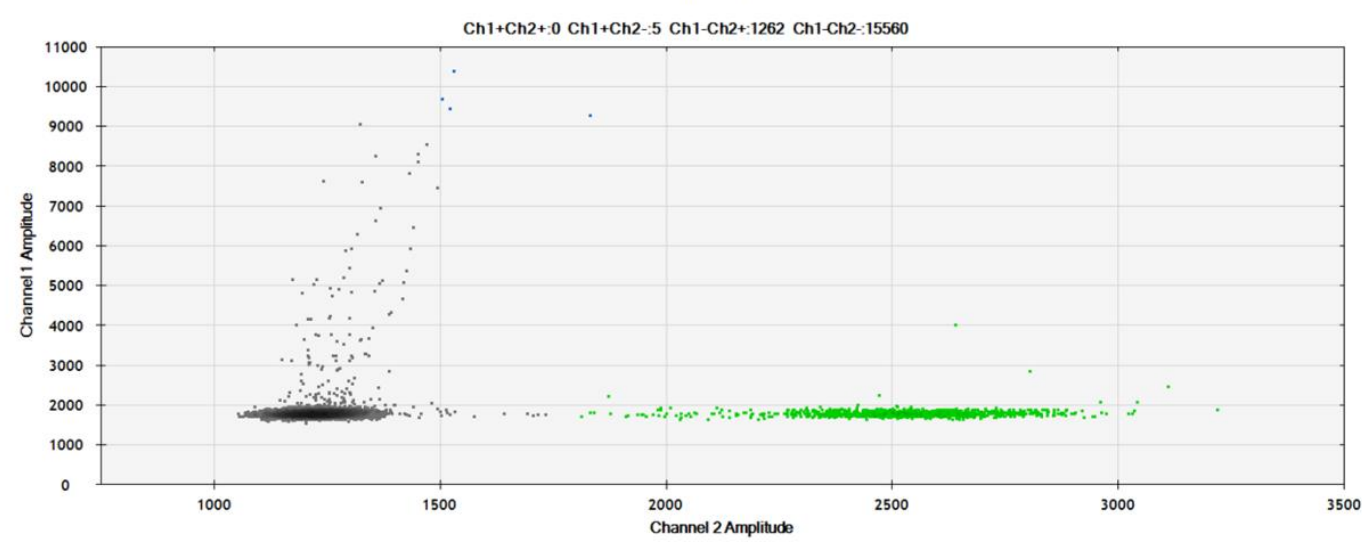

c)

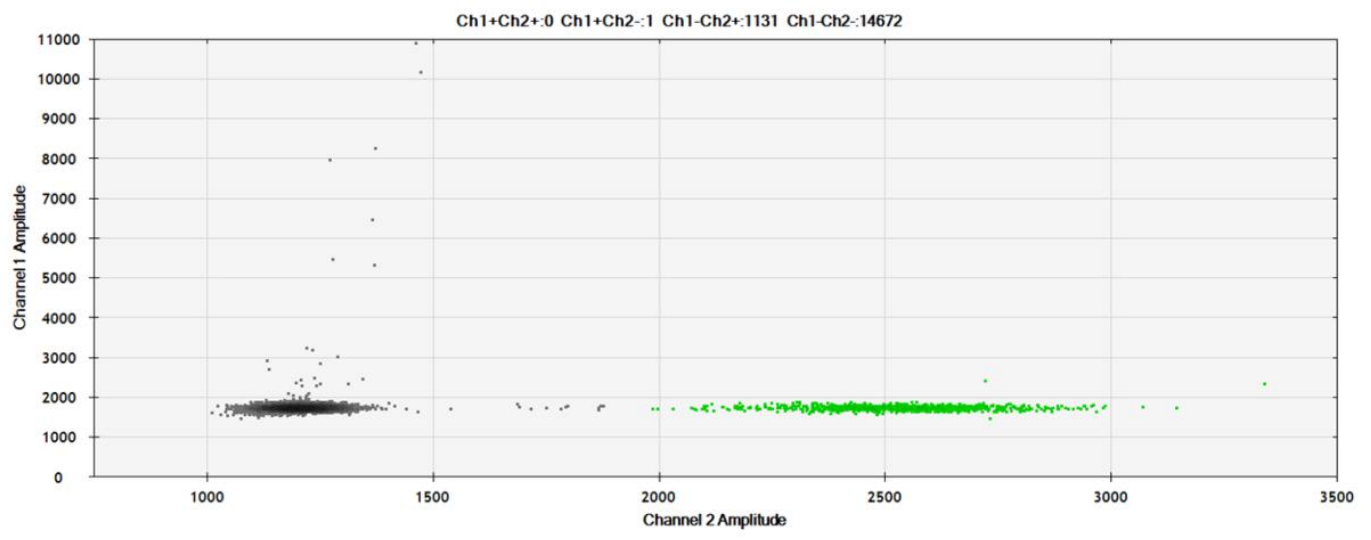

Figure S8. 2-D plot of droplet fluorescence for negative control of locus 1: a) P3, instead of P2, was used; b) no reporter stand $\mathbf{R 1}$; c) no Ampligase. 


\section{Quantification modeling}

The encapsulation maximum of one target amplicon in one droplet to generate a positive or negative signal is the ideal scenario for our situation. If a droplet contains more than one detection amplicon, for example, one contains one fdC and one cytosine, it will show a positive signal, and the negative cytosine signal vanishes.

The probability for two or more detection amplicons to get into one droplet can be calculated according to the Poisson distribution, i.e. a discrete random variable $\mathrm{X}$ complies the Poisson distribution with parameter $\lambda>0$, if, for $\mathrm{k}=0,1,2, \ldots$, the probability mass function of $\mathrm{X}$ is given by:

$$
f(k ; \lambda)=\operatorname{Pr}(\mathrm{X}=k)=\frac{\lambda^{k} e^{-\lambda}}{k !}
$$

where e is Euler's number and $k$ ! is the factorial of $k$.

Table S2 Poisson distribution probabilities of genome copies in the droplet.

\begin{tabular}{lllllll}
\hline \multirow{2}{*}{$\begin{array}{l}\text { input } \\
\mathrm{ng}\end{array}$} & \multirow{2}{*}{$\lambda$} & \multicolumn{5}{c}{$k$} \\
\cline { 3 - 7 } 3 & 0.05 & $4.8 \%$ & $0.1 \%$ & $0.0 \%$ & $0.0 \%$ & $0.0 \%$ \\
6 & 0.10 & $9.0 \%$ & $0.5 \%$ & $0.0 \%$ & $0.0 \%$ & $0.0 \%$ \\
9 & 0.15 & $12.9 \%$ & $1.0 \%$ & $0.0 \%$ & $0.0 \%$ & $0.0 \%$ \\
10 & 0.17 & $14.1 \%$ & $1.2 \%$ & $0.1 \%$ & $0.0 \%$ & $0.0 \%$ \\
15 & 0.25 & $19.5 \%$ & $2.4 \%$ & $0.2 \%$ & $0.0 \%$ & $0.0 \%$ \\
20 & 0.33 & $23.9 \%$ & $4.0 \%$ & $0.4 \%$ & $0.0 \%$ & $0.0 \%$ \\
30 & 0.50 & $30.3 \%$ & $7.6 \%$ & $1.3 \%$ & $0.2 \%$ & $0.0 \%$ \\
40 & 0.67 & $34.2 \%$ & $11.4 \%$ & $2.5 \%$ & $0.4 \%$ & $0.1 \%$ \\
\hline
\end{tabular}

For example, the mass of a mouse genome is approximately $3.0 \mathrm{pg}\left(3.0 \times 10^{-12} \mathrm{~g}\right)$. If 30 ng for a $20 \mu \mathrm{L}$ reaction is used, 10,000 genomes will be distributed into 20,000 droplets. So, $\lambda$ equals to $10,000 / 20,000=0.50$. Let $\mathrm{X}=1$, then $f(1 ; 0.50)=0.303$; let $\mathrm{X}=2$, then $f(2 ; 0.50)=0.076$. This means $30.3 \%$ of the droplets, instead $50 \%$ of the droplet, contain a single copy while $7.6 \%$ of the droplets contain two copies. Extensive distribution probabilities are listed in Table S2. If less than $9 \mathrm{ng}$ is settled in a $20 \mu \mathrm{L}$ reaction, the probability to have two copies inside one droplet will be lower than $1 \%$. For the ease of calculation, $6 \mathrm{ng}$ gDNA is used for each reaction of $20 \mu \mathrm{L}$, corresponding to ca. $90 \mathrm{copy} / \mu \mathrm{L}$. 
a)

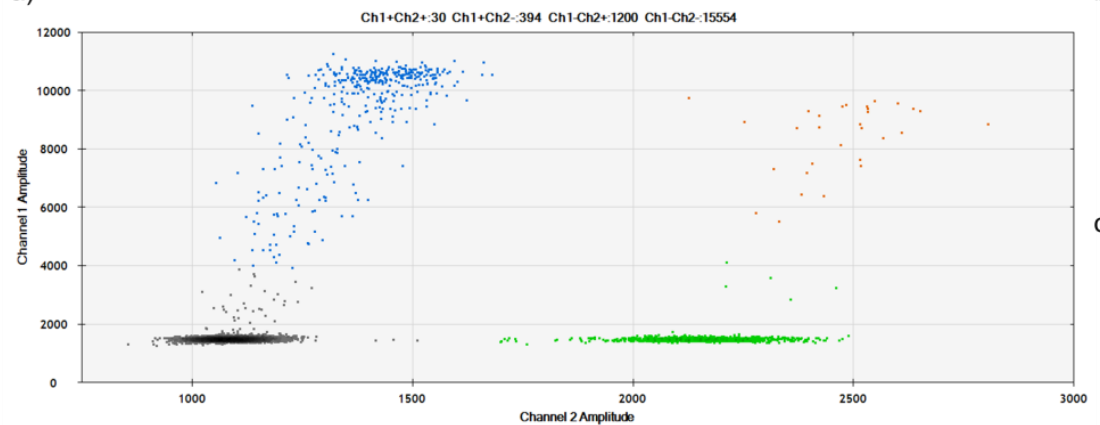

b)

\begin{tabular}{c|c} 
Ch1 + & Ch1 + \\
Ch2 - & Ch2+ \\
\hline Ch1 - & Ch1- \\
Ch2- & Ch2 +
\end{tabular}

c)

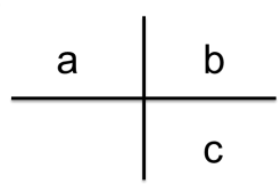

Figure S9. ddPCR output and modeling: a) 2-D plot of droplet fluorescence for illustration; b) clusters separation in four quadrants; c) algebraic simplification of counting numbers of the clusters.

As shown in Figure $\mathrm{S} 8, \mathrm{Ch} 1+\mathrm{Ch} 2+$ (yellow) refers to droplets with both positive signals; Ch1+Ch2- (blue) refers to droplets with only detection (report strand) signal; Ch1-Ch2+ (green) refers to droplets with only reference (gDNA) signal; Ch1-Ch2(black) refers to droplets without target locus and ligated product; AD refers to all the droplets accepted; resolution refers to the separation of the clusters.

In principle, $\mathrm{Ch} 1+\mathrm{Ch} 2+$ shows the droplets that contain $\mathrm{fdC}$ sites in the target locus; Ch1+Ch2- indicates false-positive signals due to unspecific amplification and the dissociated ligated products; Ch1-Ch2+ shows the droplets containing only the target gDNA.

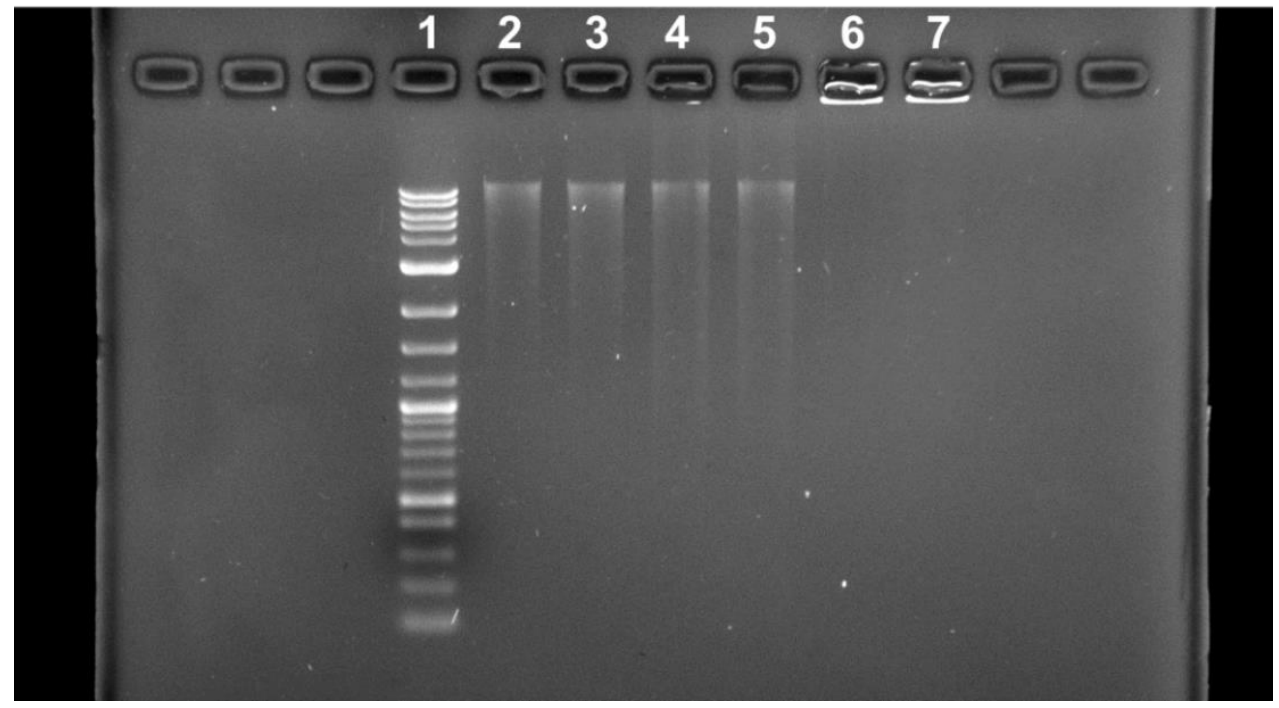

Figure S10. Agarose gel showing gDNA degradation: Line 1, $\log 2$ marker; line 2,3, gDNA (150 ng) after crosslinking; line 4,5, gDNA (150 ng) after ligation cycle, $95^{\circ} \mathrm{C}$ for $3 \mathrm{~min}$, then 10 cycles of $94^{\circ} \mathrm{C}$ for $1 \mathrm{~min}$ and $60^{\circ} \mathrm{C}$ for $1 \mathrm{~h}$; line 6,7 , gDNA (150 ng). 
Without considering the dissociation of the ligated products, the unreacted probe which remained in the system will cause unspecific amplification, i.e. $\mathrm{Ch} 1+\mathrm{Ch} 2-$ signals. Catalyst, acid buffer, and ligation cycles will cause gDNA degradation (Figure S9, giving more $\mathrm{Ch} 1+\mathrm{Ch} 2-$ false-negative signals. However, $\mathrm{Ch} 1+\mathrm{Ch} 2-$ and Ch1+Ch2- / Ch1-Ch2- resolution do not play a role in the mathematical modelling that we used.

Assuming that all $\mathrm{fdC}$ at the target site is converted to the reporter strand via crosslinking and ligation, the yield is $100 \%$. Assume that there are less than 150 copies in $1 \mu \mathrm{L}$ so that the Poisson distribution is exclusive in our model.

Let $\mathrm{a}=\mathrm{Ch} 1+\mathrm{Ch} 2-, \mathrm{b}=\mathrm{Ch} 1+\mathrm{Ch} 2+, \mathrm{c}=\mathrm{Ch} 1-\mathrm{Ch} 2+,($ Figure S8) A = Accepted droplet for the experiment entry, respectively, a', b', c', and $A^{\prime}$ for the control, i.e. TET knockout cell line.

Let $\eta=\mathrm{fdC}$ content of the target site.

Then,

$$
\eta=\frac{\mathrm{a}+\mathrm{b}-\frac{A}{A^{\prime}}\left(a^{\prime}+b^{\prime}\right)}{b+c+\left(a-\frac{A}{A^{\prime}} a^{\prime}\right) / \eta}
$$

where $\mathrm{a}-\frac{\mathrm{A}}{\mathrm{A}^{\prime}} a^{\prime}$ refers to the degraded gDNA copy containing fdC at the target site that does not show in $\mathrm{Ch} 2,\left(\mathrm{a}-\frac{\mathrm{A}}{A^{\prime}} a^{\prime}\right) / \eta$ refers to all the degraded gDNA copies. So,

$$
\eta=\frac{\left(\mathrm{b}-\frac{A}{A^{\prime}} \mathrm{b}^{\prime}\right)}{b+c}
$$

Herein, in this ideal model, without considering the dissociation of the ligated products, $\eta$ is independent of a, a', and c', i.e. genome degradation and unspecific ligation do not affect fdC percentage. Ch1+Ch2- only be resulted from the dissociation of the ligated products. Also, as shown in Figure S6 a-c, b' can be omitted. Simplified $\eta^{\prime}$

$$
\eta^{\prime}=\frac{\mathrm{a}+\mathrm{b}}{b+c}
$$

is calculated to indicate relative abundance of $\mathrm{fdC}$ at the target site.

In reality, neither the fdC probe covers all the target sites nor the reporter strand ligates to all the target-linked probe. Therefore, only relative quantification is possible in our model. 


\section{Droplet digital PCR data}

Raw data of fdC detection in $\mathrm{Tdg}^{-/-}, \mathrm{Tdg}^{+/-}$, Dnmt TKO cells for locus 1. (AD: accepted droplets)

\begin{tabular}{cccccccccc}
\hline & Ch1 & Ch2 & $1+2+$ & $1+2-$ & $1-2+$ & $1-2-$ & AD & $\eta$ & Average \\
\hline Tdg-/- & 17.6 & 67.6 & 151 & 121 & 827 & 16399 & 17502 & $27.8 \%$ & \\
Tdg-/- & 17.6 & 63.7 & 101 & 93 & 590 & 12318 & 14896 & $28.1 \%$ & $28.5 \%$ \\
Tdg-/- & 18.9 & 63.7 & 106 & 103 & 585 & 12308 & 13102 & $30.2 \%$ & \\
Tdg-/- & 28.8 & 103 & 181 & 149 & 1002 & 12743 & 14075 & $27.9 \%$ & \\
\hline Tdg+/- & 11.6 & 74.0 & 54 & 56 & 676 & 11085 & 11878 & $15.1 \%$ & \\
Tdg+/- & 11.3 & 67.2 & 54 & 70 & 698 & 12722 & 13544 & $16.5 \%$ & $15.7 \%$ \\
Tdg+/- & 10.7 & 69.6 & 52 & 83 & 806 & 13994 & 14935 & $15.7 \%$ & \\
Tdg+/- & 10.8 & 72.0 & 56 & 66 & 738 & 12490 & 13350 & $15.4 \%$ & \\
\hline Dnmt TKO & 4.0 & 115.0 & 10 & 29 & 1049 & 10327 & 11415 & $3.7 \%$ & \\
Dnmt TKO & 3.1 & 61.1 & 11 & 17 & 625 & 11913 & 12566 & $4.4 \%$ & \\
Dnmt TKO & 4.1 & 58.0 & 14 & 30 & 620 & 12508 & 13174 & $6.9 \%$ & $5.2 \%$ \\
Dnmt TKO & 2.8 & 60.6 & 8 & 21 & 600 & 11484 & 12119 & $4.8 \%$ & \\
Dnmt TKO & 5.7 & 96.0 & 35 & 28 & 986 & 11998 & 13047 & $6.2 \%$ & \\
\hline
\end{tabular}




\section{Locus $1 \mathrm{Tdg}^{-/-} \mathrm{mES}$ cell sample}
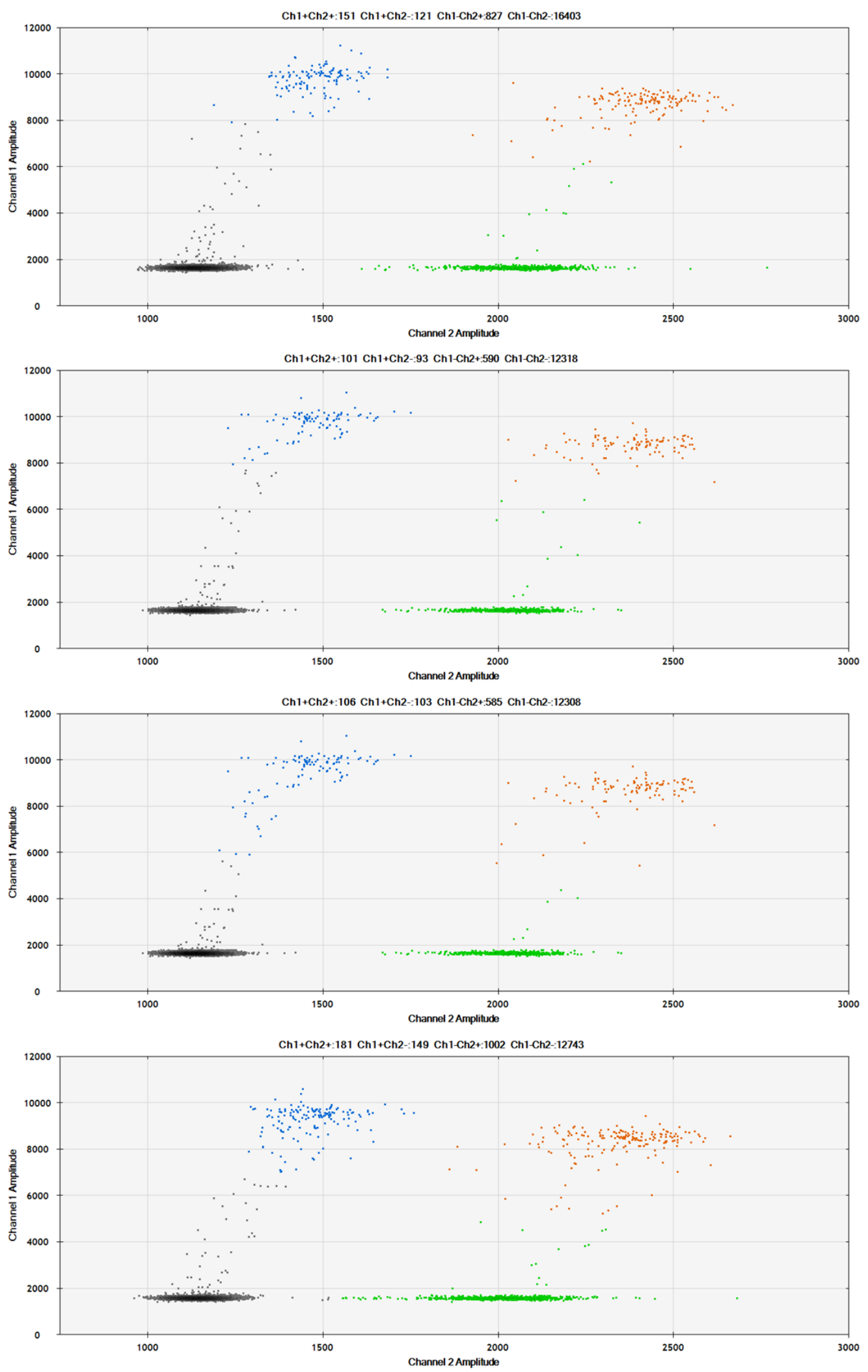


\section{Locus $1 \mathrm{Tdg}^{+/-} \mathrm{mES}$ cell sample.}
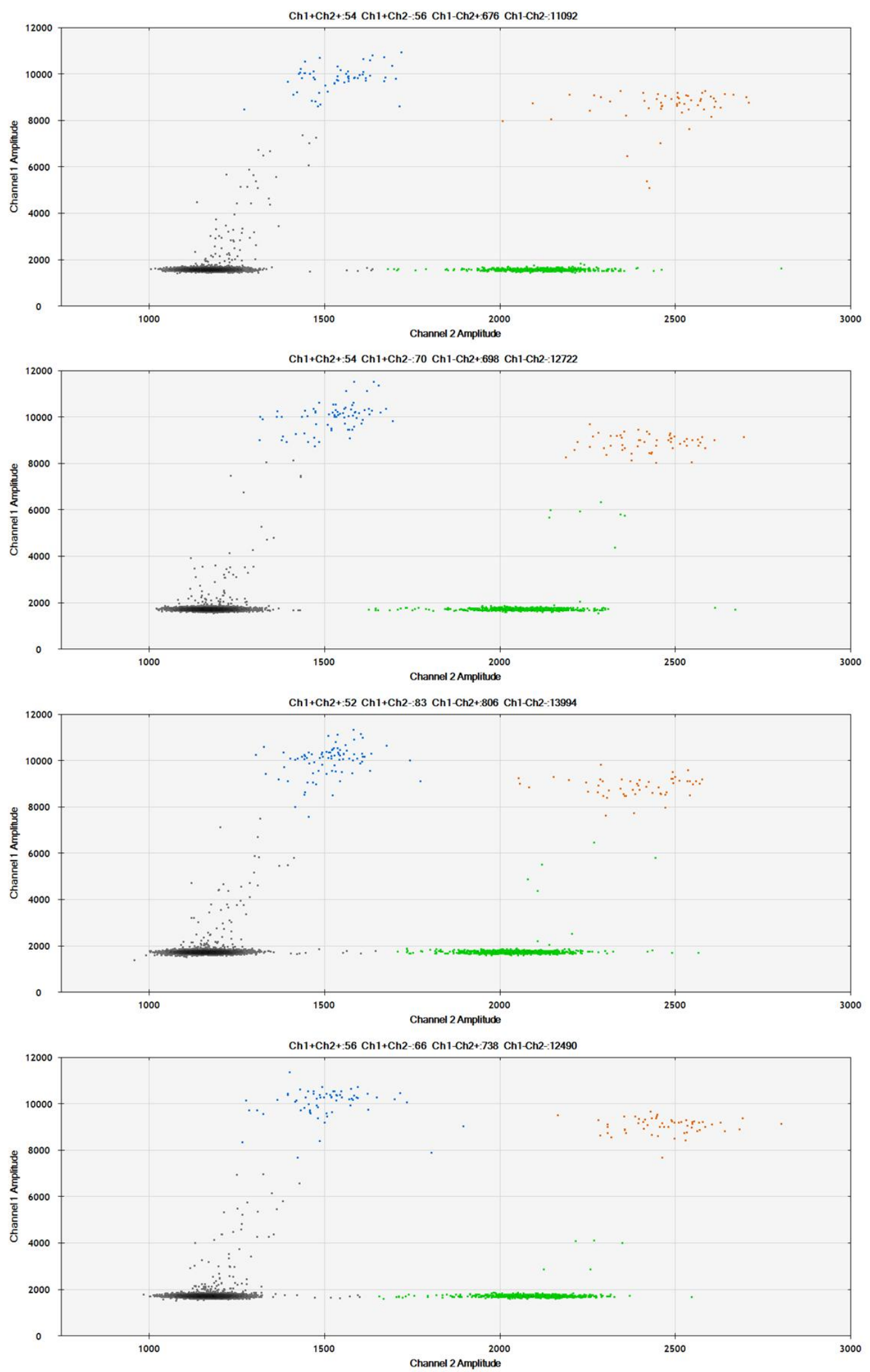
Locus 1 Dnmt TKO mES cell sample.
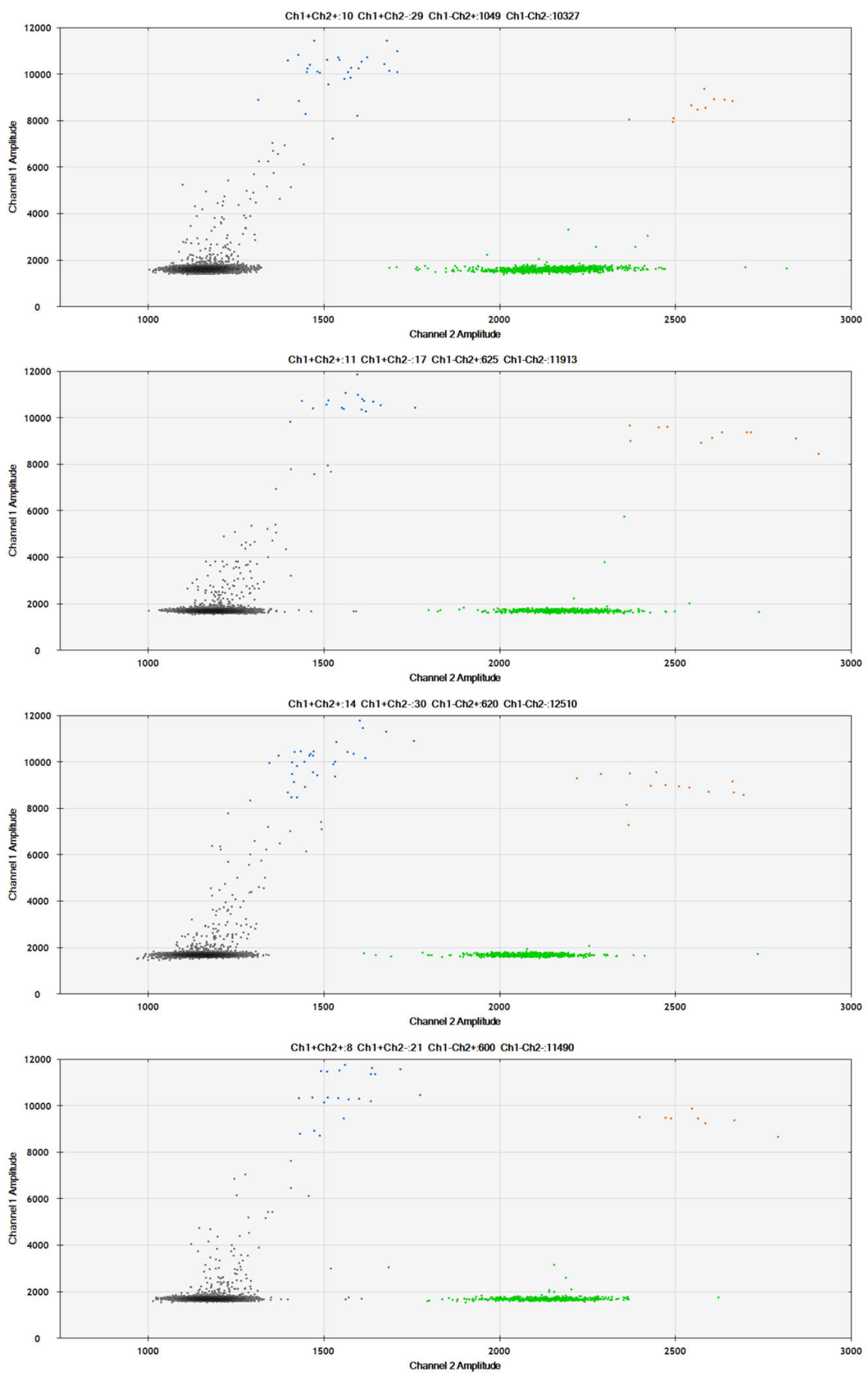
Locus 1 Raw data of fdC detection in wild-type cells during priming.

\begin{tabular}{lccccccccc}
\hline & Ch1 & Ch2 & $1+2+$ & $1+2-$ & $1-2+$ & $1-2-$ & AD & $\eta$ & Average \\
\hline WT0 & 5.4 & 108 & 20 & 34 & 1017 & 10787 & 11858 & $5.21 \%$ & \\
WT0 & 6.8 & 110 & 30 & 58 & 1336 & 13841 & 15265 & $6.44 \%$ & $6.06 \%$ \\
WT0 & 6.6 & 112 & 26 & 53 & 1255 & 12738 & 14072 & $6.17 \%$ & \\
WT0 & 7.8 & 108 & 23 & 58 & 1241 & 13060 & 14382 & $6.41 \%$ & \\
\hline WT2 & 9.7 & 89.2 & 40 & 98 & 1193 & 15552 & 16883 & $11.19 \%$ & \\
WT2 & 10.2 & 88.7 & 35 & 105 & 1249 & 15948 & 17337 & $10.90 \%$ & \\
WT2 & 10.8 & 93.0 & 35 & 96 & 1168 & 14476 & 15771 & $10.89 \%$ & $10.90 \%$ \\
WT2 & 10.2 & 96.0 & 54 & 94 & 1279 & 15637 & 17064 & $11.10 \%$ & \\
WT2 & 6.3 & 56.2 & 19 & 65 & 744 & 15582 & 16410 & $11.01 \%$ & \\
WT2 & 6.0 & 57.3 & 27 & 54 & 759 & 15780 & 16620 & $10.31 \%$ & \\
\hline WT4 & 6.2 & 68.0 & 19 & 30 & 501 & 8702 & 9252 & $9.42 \%$ & \\
WT4 & 5.4 & 68.4 & 26 & 46 & 811 & 13942 & 14821 & $8.60 \%$ & $8.76 \%$ \\
WT4 & 4.5 & 59.0 & 14 & 24 & 477 & 9449 & 9964 & $7.74 \%$ & \\
WT4 & 5.8 & 64.5 & 23 & 43 & 688 & 12579 & 13333 & $9.28 \%$ & \\
\hline WT6 & 11.1 & 117 & 42 & 67 & 1081 & 10691 & 11881 & $9.71 \%$ & \\
WT6 & 8.2 & 114 & 28 & 41 & 888 & 9000 & 9957 & $7.53 \%$ & $8.67 \%$ \\
WT6 & 9.8 & 120 & 32 & 41 & 820 & 7909 & 8802 & $8.57 \%$ & \\
WT6 & 8.5 & 114 & 43 & 57 & 1086 & 11010 & 12196 & $8.86 \%$ & \\
\hline
\end{tabular}

Locus 2 Raw data of fdC detection in $\mathrm{Tdg}^{-/-}, \mathrm{Tdg}^{+/-}$cells

\begin{tabular}{llccccccccc}
\hline Well & & Ch1 & Ch2 & $1+2+$ & $1+2-$ & $1-2+$ & $1-2-$ & AD & $\eta$ & Average \\
\hline H04 & Tdg-/- & 10.5 & 52 & 55 & 92 & 650 & 15671 & 16468 & $20.9 \%$ & \\
E06 & Tdg-/- & 20.8 & 115 & 88 & 133 & 1084 & 11285 & 12590 & $18.9 \%$ & \\
F06 & Tdg-/- & 22.5 & 114 & 98 & 173 & 1226 & 12805 & 14302 & $20.5 \%$ & $19.8 \%$ \\
G06 & Tdg-/- & 20.1 & 109 & 94 & 149 & 1178 & 12927 & 14348 & $19.1 \%$ & \\
H06 & Tdg-/- & 21.8 & 116 & 90 & 159 & 1179 & 12141 & 13569 & $19.6 \%$ & \\
\hline B09 & Tdg+/- & 5.5 & 66 & 28 & 49 & 884 & 15696 & 16657 & $8.4 \%$ & \\
A10 & Tdg+/- & 5.9 & 59 & 13 & 29 & 400 & 8002 & 8444 & $10.2 \%$ & $9.2 \%$ \\
E01 & Tdg+/- & 8.3 & 96 & 43 & 78 & 1299 & 15749 & 17169 & $9.0 \%$ & \\
G01 & Tdg+/- & 8.1 & 93 & 39 & 73 & 1205 & 15070 & 16387 & $9.0 \%$ & \\
\hline
\end{tabular}

